\section{Aportaciones al conocimiento de las técnicas constructivas altomedievales en Álava, Guipúzcoa y Vizcaya'}

\author{
A. Azkarate Garai-Olaun, L. SÁnchez Zufiaurre \\ Grupo de Investigación en Arqueología de la Arquitectura \\ de la Universidad del País Vasco
}

\section{Resumen}

El estudio de las técnicas constructivas altomedievales en el País Vasco no ha sido un tema de investigación muy difundido hasta hace pocos años, en parte debido a que las herramientas teóricas y metodológicas no estaban suficientemente desarrolladas. Esta situación está empezando a ser solventada gracias a una serie de investigaciones que, apoyándose en el desarrollo de la Arqueología de la Arquitectura, están sacando a la luz un número relevante de evidencias así como nuevas líneas teóricas para interpretarlas. En el presente trabajo se pretende, en primer lugar, identificar aquellas construcciones que puedan ubicarse cronológicamente en la Alta Edad Media. Una vez establecidas sus características se busca delinear, a modo de boceto inicial, la evolución de las técnicas edificatorias durante los siglos VIII al XI. Con ello esperamos llegar a hacer visibles a los responsables de su ejecución, sean los propios usuarios de los edificios o grupos de constructores especializados.

Palabras clave: Técnicas constructivas, Alta Edad Media, País Vasco

\begin{abstract}
Up to a few years ago, the study of High-Medieval building techniques had not been an overly popular subject for research in the Basque Country, partly because of the relative lack of development of both theoretical and methodological tools. The tide is now turning in part due to a series of investigations that, with backing in the development of Building Architecture, are unearthing a relevant number of evidences, as well as new theoretical approaches to interpret them. The following paper intends to identify those buildings that can be chronologically placed within the High Middle Ages as well as establish its features, in order to provide a preliminary sketch of the evolution of building techniques from the $\mathrm{VIII}^{\text {th }}$ to the $\mathrm{XI}^{\text {th }}$ centuries. Our intent is to make visible the people responsible for their execution, whether the users of the buildings themselves or group of specialized builders.
\end{abstract}

Key words: Building techiques, Early Medieval, Basque Country

1 Este artículo es el resultado de un esfuerzo colectivo cuya «creatividad se pone principalmente de manifiesto como un fenómeno de grupo, en el que la contribución individual se halla aparentemente subsumida como parte del proceso y el control de calidad se ejerce como un proceso socialmente ampliado que acomoda muchos intereses en un proceso de aplicación dado» (GibBONS, 1997: 21). Una larga década de experimentación en el ámbito de la gestión integral del patrimonio cultural (documentación, conservación y difusión) ha abierto distintas vías temáticas en las que se va profundizando en gradientes diversos. No podía ser de otra manera en una investigación contextualizada que mira permanentemente al propio "contexto de aplicación». La tutela de más de 500 edificios religiosos por parte de las instituciones alavesas está siendo posible gracias a la generación de unos protocolos de intervención que, pese a los inevitables defectos, constituyen un referente para otros territorios. En ese contexto (todavía en curso) nació la Tesis Doctoral defendida por Leandro Sánchez Zufiaurre bajo la dirección de Agustín Azkarate y que verá la luz en breve en forma de publicación monográfica

\section{LOS CONTEXTOS Y SUS EVIDENCIAS}

El objetivo básico de este breve trabajo no es otro que ofrecer un estado de la cuestión actualizado sobre las técnicas constructivas medievales en el País Vasco a partir de las evidencias que conocemos hasta el presente, tarea nada fácil dado el estado fragmentario de la muestra y su desigual distribución territorial. Poco a poco, no obstante, vamos conociendo datos suficientes como para elaborar un cuadro general y avanzar, incluso, algunas hipótesis de carácter interpretativo.

Nos centraremos básicamente en los siglos altomedievales (siglos VIII-XI), sin apenas tomar en cuenta los elementos de época tardoantigua. No renunciaremos, sin embargo, a algunas consideraciones finales sobre este periodo — casi a modo de addenda - especialmente en cuestiones de arquitectura rupestre ${ }^{2}$. Dividiremos el trabajo en dos partes, de naturaleza descriptiva la primera y de carácter más interpretativo la segunda.

El estudio de las técnicas constructivas requiere contar, en un primer nivel de análisis arqueográfico y arqueométrico, con un número adecuado de evidencias con una contextualización estratigráfica y una datación fiables. Un muestreo suficiente y de calidad constituye, sin duda, la premisa fundamental y previa a un nivel de análisis posterior de carácter arqueológico en el que la interpretación y contextualización históricas se convierten en objetivo prioritario ${ }^{3}$.

Hemos mencionado ya la naturaleza limitada de las fuentes disponibles, incluso para épocas bajomedievales ${ }^{4}$. Durante el último decenio, sin embargo, se está realizando un considerable esfuerzo en el contexto de los proyectos de investigación llevados a cabo desde el Grupo de Investigación en

(SÁNCHEZ ZufiaurRe, e.p.). De su contenido es deudor una parte de este trabajo. Su ejecución fue financiada tanto por un proyecto de la Universidad del País Vasco (La evolución de las técnicas constructivas en Álava durante las edades media y moderna a la luz de la Arqueología. Código 9/UPV/EHU0155.130-12788/2000) como por el propio Grupo de Investigación en Arqueología de la Arquitectura. El estudio de la arquitectura rupestre que ha retomado A. Azkarate, tras un paréntesis de bastantes años, está siendo financiado por el Departamento de Cultura del Gobierno Vasco.

${ }^{2}$ Este capítulo de la arquitectura está siendo objeto de un nuevo estudio por parte de uno de los firmantes de este trabajo, dada la importancia que tuvo como elemento organizador y catalizador de numerosos asentamientos humanos que a lo largo del tiempo fueron cuajando en las aldeas medievales

${ }^{3}$ Lamentablemente, y tal como hemos señalado en alguna ocasión (AzKARATE, 2004), la mala conciencia contemporánea generada por decenios de tiranía positivista ha llevado a algunos arqueólogos a corregir el rumbo aventurándose a la generación de modelos interpretativos débilmente apoyados en evidencias no contrastadas ni actualizadas suficientemente.

${ }^{4}$ Sobre la arquitectura románica y posterior se ha escrito mucho. La calidad de los trabajos, sin embargo, es muy desigual, echándose en falta, en general, la presencia de análisis de carácter estratigráfico y constructivo. 
Arqueología de la Arquitectura de la Universidad del País Vasco (GIAA). A pesar de ello existen todavía algunas carencias importantes. Nos referimos, especialmente, a la desigual distribución espacial de las evidencias conocidas: la mayoría de ellas se encuentran en Álava, siendo aún incipientes los estudios sobre el tema en los territorios vecinos. Afortunadamente la existencia de ámbitos geográficos que comparten rasgos de carácter fisiocrático con los espacios vecinos permite adivinar dinámicas similares para los territorios guipuzcoano y vizcaíno.

\section{1. Álava}

\subsubsection{La arquitectura doméstica de época altomedieval en Vitoria-Gasteiz}

En otros lugares hemos tenido ocasión de avanzar algunos resultados sobre las excavaciones arqueológicas que se vienen llevando a cabo en la parte más alta del Casco Histórico de Vitoria-Gasteiz (AzKarate et alii, 2001; AzKarate, Quirós, 2001; Azkarate, Solaun, 2003) por lo que no incidiremos en algunos aspectos ya conocidos. Este texto, por el contrario, nos servirá para incorporar algunas novedades confirmar algunas informaciones y/o corregir algunas otras vertidas en los avances anteriores.

En el conjunto de excavaciones que el Grupo de Investigación en Arqueología de la Arquitectura ha efectuado en el Casco Histórico se han documentado hasta el momento los tipos siguientes de estructuras domésticas, adscribibles todos ellos a los siglos VIII-XI d.C.5 (Fig. 1).

-Estructura a nivel del suelo, de planta circular ( $4 \mathrm{~m}$. diám.) bien delimitada por una acanaladura tallada en la roca; estructura portante de postes verticales. Íntegramente construida en materiales perecederos. Cronología: VIII-X. d.C. Tipo AIII: 6.3.0. (VAlENTI, 1996).

-Estructuras a nivel de suelo, con planta trapezoidal organizada en dos estancias y alzado construido sobre diez postes perimetrales que liberan un espacio interior de $c a$. 12 metros cuadrados en un caso y $c a$. de 18 en el otro. En este último, una de las estancias tiene en su interior un «fondo de cabaña» de reducidas dimensiones. Para su construcción se recurrió exclusivamente a materiales perecederos. Cronología: VIII-X d.C. Tipo AI: 3.3.0.

-Estructura a nivel de suelo levantada sobre grandes postes de madera. En lo que es visible organiza un espacio de grandes dimensiones, a modo de una longhouse, cerrado

\footnotetext{
5 Queda fuera del ámbito de este trabajo la riquísima tipología constructiva que, sin solución de continuidad, se ha documentado para todos los siglos bajomedievales y de época moderna y que trataremos en otra ocasión.
}

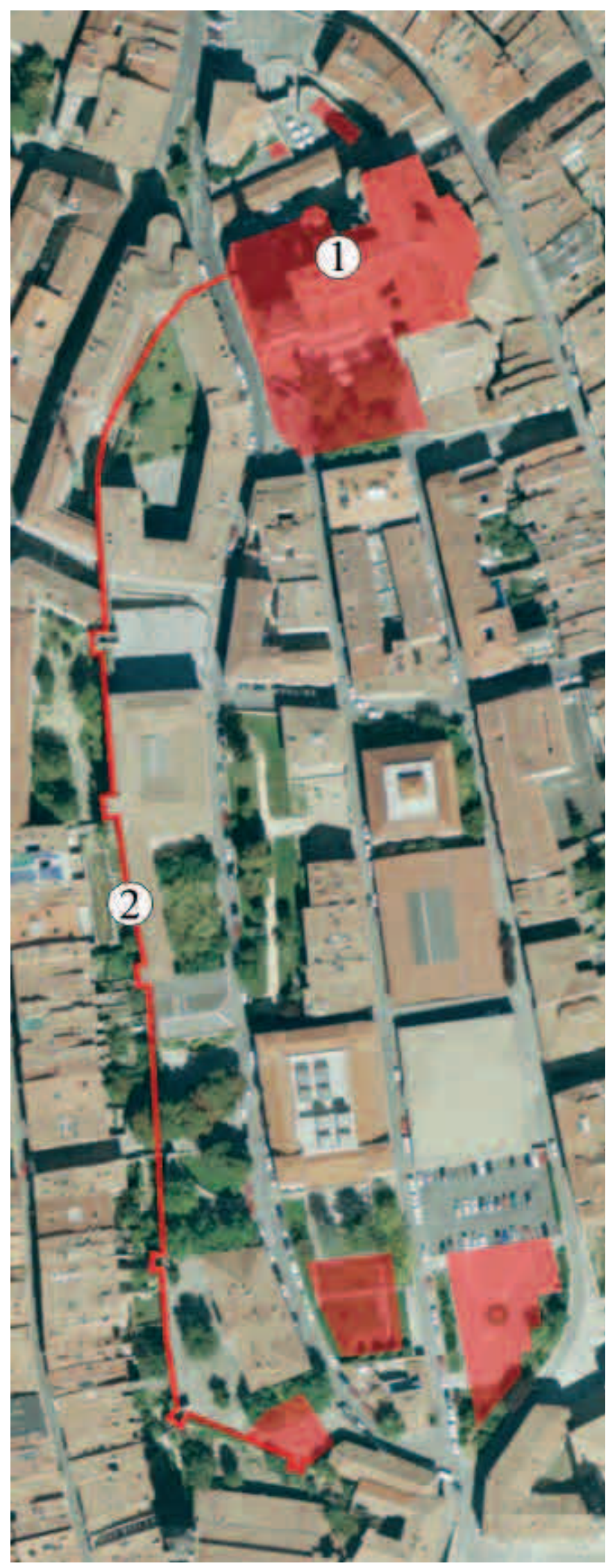

Fig. 1. Imagen aérea del espacio que ocupaba la primitiva Gasteiz: áreas excavadas y muralla primitiva en su lado occidental 

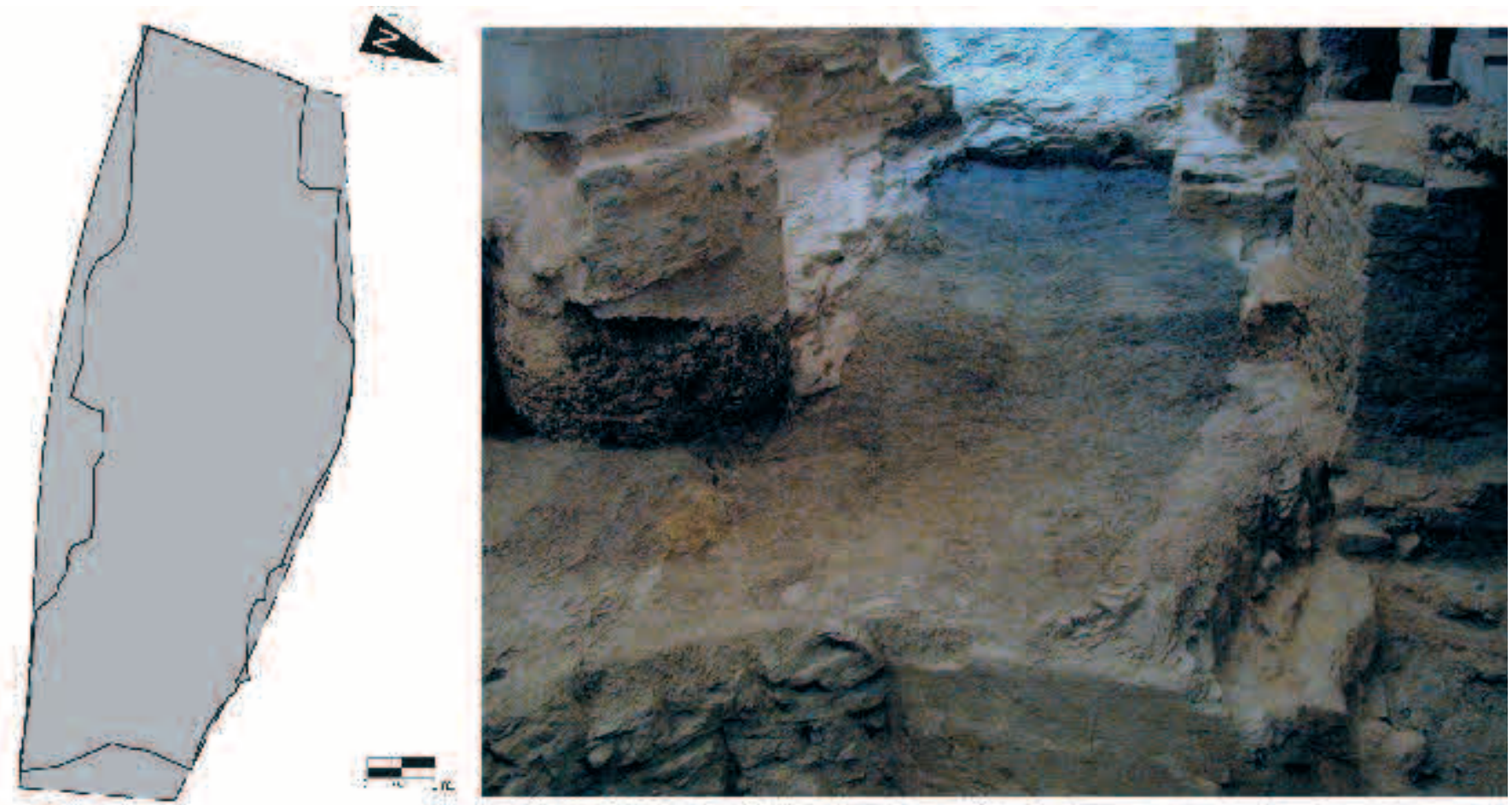

Fig. 2. Fondo de cabaña excavado en la nave norte de la Catedral de Santa María (ss. VIII-x)

en su lado occidental por una gran acanaladura de línea ligeramente curva, y en sus lados meridional y septentrional por diversos agujeros de poste. Su interior presenta también diversos agujeros de poste que pudieron organizar el espacio de forma compartimentada. Cronología: VIII-X d.C. Tipo AI: 9.3.0.

-Estructura levantada sobre durmientes de madera en los que se ensamblaron los pies derechos de las paredes. Conforma dos estancias contiguas separadas por un medianil, construidas totalmente en madera aunque con una técnica distinta a la descrita para los tipos anteriores. La estructura de la cabaña se ejecutó, como queda dicho, utilizando como base durmientes de madera de sección rectangular que recibieron los pies derechos del entramado de las paredes, ensamblados al durmiente a caja y espiga. La estancia meridional tuvo hasta tres suelos y cuatro hogares sucesivos, evidenciando reformas internas significativas, mientras que la septentrional no presentaba evidencias de haber sido modificada durante su periodo de uso (AZKARATE, 2003). Cronología: s. XI. Tipo AII Blockbau

-Estructuras semiexcavadas en la roca («fondos de cabaña»). Son varios los ejemplos localizados, en algún caso de notables dimensiones, como el fondo de cabaña ubicado en la nave septentrional de la actual catedral de Santa María, con más de 8 metros de longitud y ca. 2,5 m de anchura. Cronología: ss. VIII-X (Fig. 2).
-Estructuras mixtas. Las dataciones radiocarbónicas fechan en el siglo X el momento de transición de las construcciones levantadas íntegramente con materiales perecederos a la arquitectura que denominamos $\operatorname{mixta}^{6}$ y cuyo exponente más relevante es un gran edificio construido en el extremo oriental de la plaza de Santa María, de orientación norte-sur y planta rectangular. Sus más de veintiún metros de longitud dan cuenta de la importancia de esta estructura doméstica, compartimentada en tres áreas distintas de uso. Su técnica constructiva es la que viene siendo definida como "mixta», caracterizada por el empleo de zócalos de piedra sobre los que se alzan muros de tapial. Provisto de suelos de arcilla batida sobre los que asentar hogares o fuegos bajos, cabe suponer el empleo de cubiertas perecederas al no haberse registrado ningún resto material cerámico (teja) o pétreo (lajas esquistosas) (Fig. 3).

\subsubsection{Las murallas de Gasteiz}

El «descubrimiento» de las primitivas murallas de Vitoria-Gasteiz es muy reciente. Cuando hablamos de descubrimiento obviamente no utilizamos esta expresión en su estricta

6 UE 18587. Edad C-14: $1061+/-36$ BP. Edad calibrada (OxCal v3.5 program): al 68,2 \% (1 sigma): 900-920 AD (11,2\%); 960-1020 AD (57.0 \%). Al 95,4 \% (2 sigmas) 890-1030 AD. (Laboratorio del CSIC1724). 


\section{A}
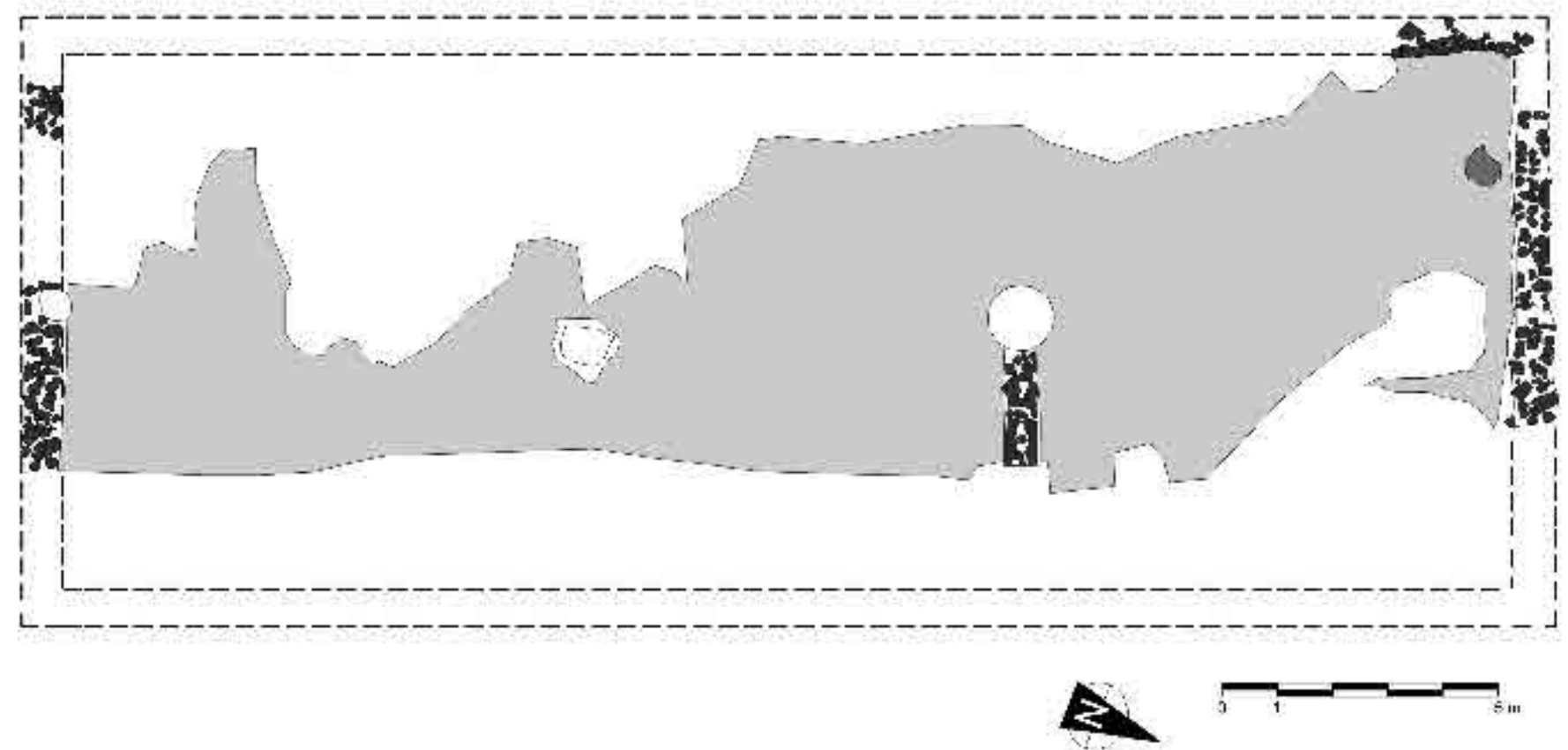

B

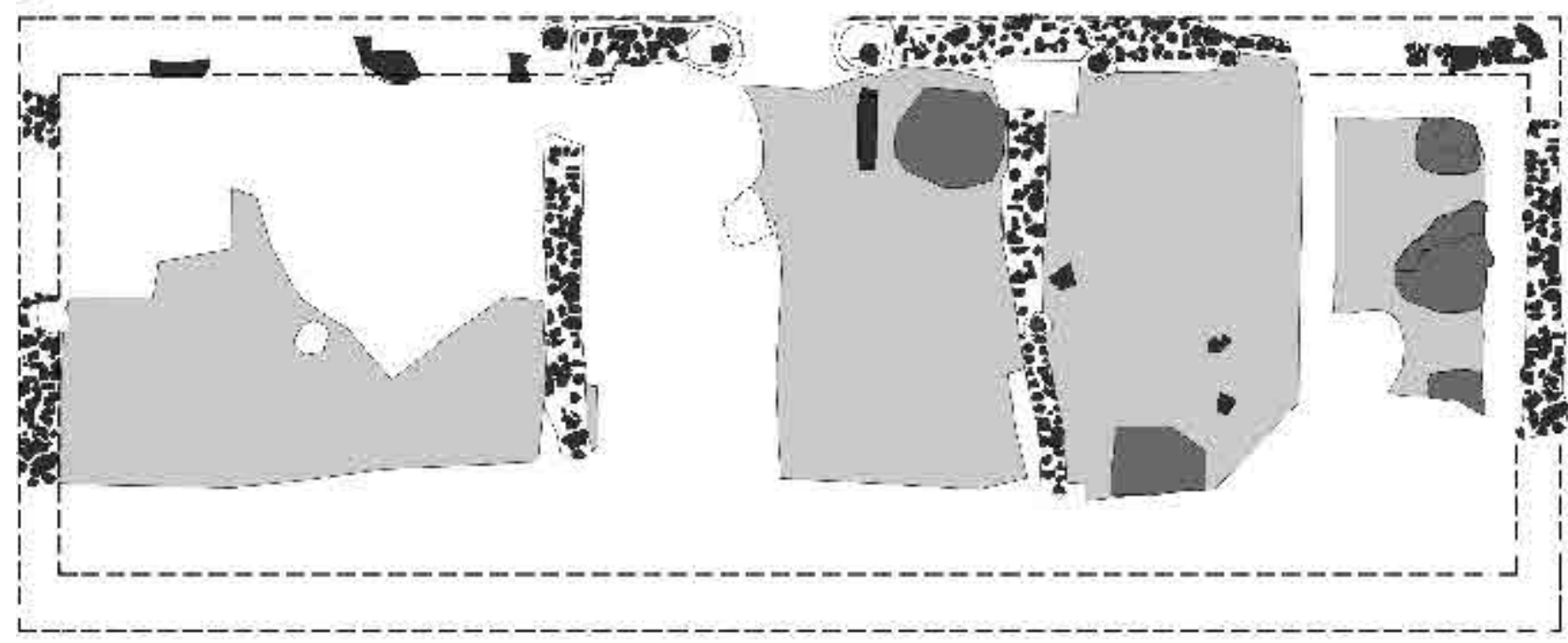

Surlo Esugga bajo Estructura
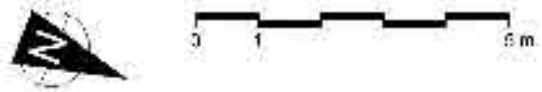

Fig. 3. Gran estructura doméstica sobre zócalos de piedra exhumada en el lado oriental de la plaza de Santa María. a) 2.a mitad del siglo x. b) 2.a mitad del siglo xI

literalidad —ahí estaban las murallas y se conocían de antiguo $^{7}$ - sino en su sentido social. Sólo muy recientemente las primitivas murallas de la vieja Gasteiz han comenzado a

7 Véase R. De Apraiz, La Muralla del primitivo Vitoria, Boletín de la Real Sociedad Vascongada de Amigos del País, Año, 9, cuaderno 2, 1953, pp. 169-190. ser reconocidas por la ciudadanía. Ni se conocían en su materialidad (ocultas por las traseras de las viviendas de las calles Correría y Cuchillería), ni se sabían ubicar correctamente en su tiempo histórico (se creían obra de Sancho el Sabio, 1181) cuando en realidad son un siglo anteriores (AZKARATE, LASAGABASTER, e.p.). Tras las investigaciones arqueológicas llevadas a cabo, sabemos hoy en día que fue durante la 
segunda mitad del siglo XI cuando el asentamiento campesino cuya arquitectura doméstica hemos descrito en el capítulo anterior, se rodeará de una gran muralla de piedra.

Tras las campañas de excavación efectuadas, estamos en condiciones de establecer con seguridad tanto su trazado como las técnicas constructivas empleadas por los artífices de la obra. El encintado pétreo - con una anchura media de 1,5 metros- presenta una planta quebrada formada por tramos rectos de $c a .17 \mathrm{~m}$., delimitados por torreones avanzados de planta rectangular. Estos torreones poseen unas dimensiones que giran en torno a los 4,80 m. de longitud y $3,75 \mathrm{~m}$. de anchura total, sobresaliendo de la línea exterior de la muralla ca. 2,30 metros. La óptima conservación del torreón situado a un lado de la calle Fray Zacarías nos permite suponer una altura cuando menos superior a los 6,60 m., así como otros datos acerca de su estructura interior. Se trata de una estructura abierta actualmente a la gola, aunque en origen parece que pudo presentar algún tipo de cierre formado por materiales perecederos, ya que en su base se conserva la cimentación de un posible apoyo corrido. Varios mechinales abiertos a media altura nos informan también sobre la existencia de dos pisos, el superior con un pequeño vano asaetado (Fig. 4).

Son tres los tipos de piedra utilizados en su construcción, cada uno de ellos coincidente grosso modo con un emplazamiento específico en la estructura defensiva: a) La caliza margosa local — extraída del propio substrato rocoso de la colina - se utilizó profusamente en las cimentaciones ordenándose las lajas en un opus spicatum que no supera nunca las tres hiladas. b) Se recurrió a las calcarenitas de Olárizu —rocas calcáreas procedentes de las proximidades de Vitoria y caracterizadas por su alta resistencia mecánica- para levantar el grueso de la construcción mediante el clásico muro de tres hojas. Sus paramentos exteriores están confeccionados con un sencillo aparejo a soga de bloques organizados en tendeles horizontales de una considerable regularidad. Todos los mampuestos llevan un mínimo trabajo de desbaste o careado (no podríamos hablar de escuadrado
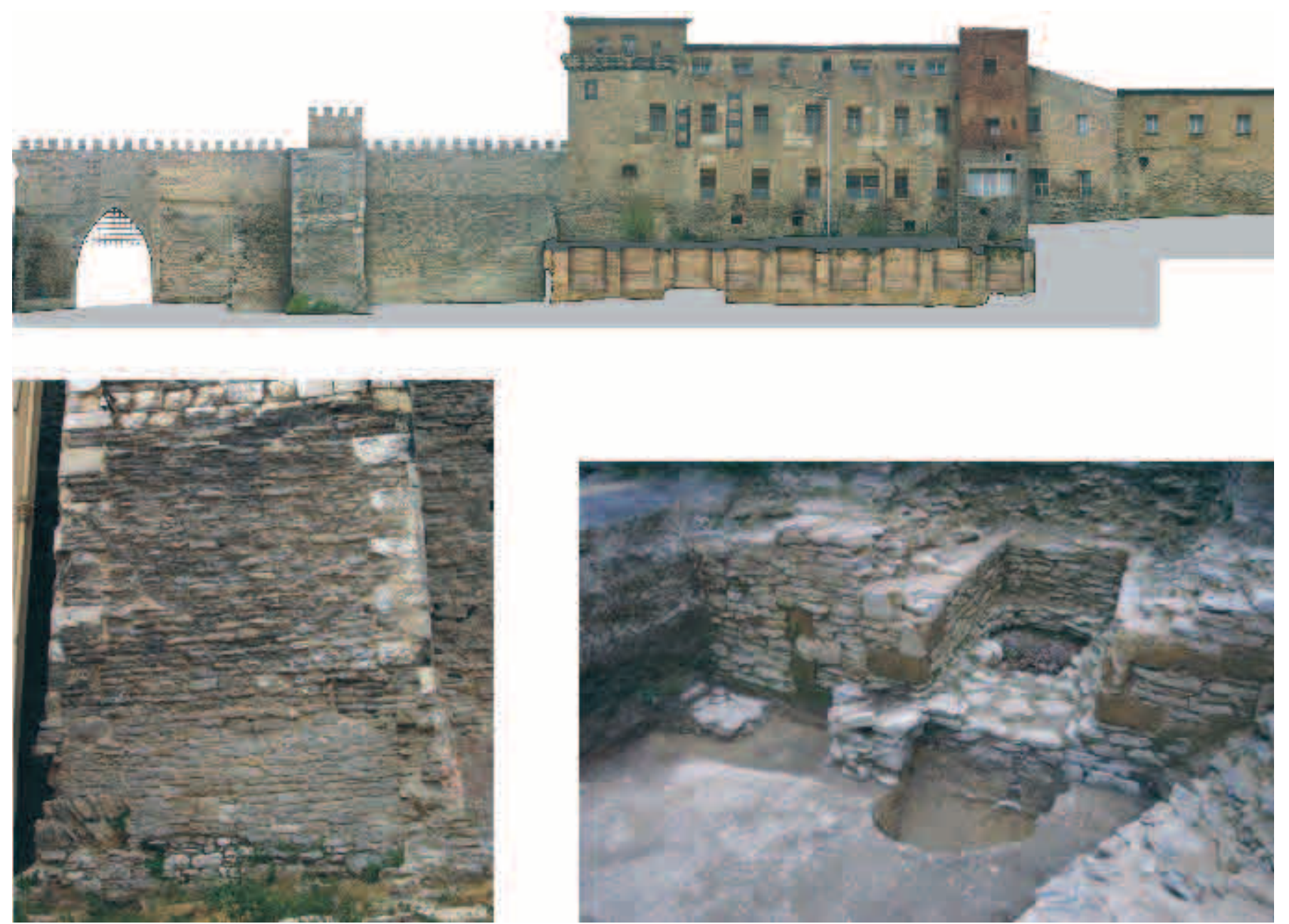

Fig. 4. Muralla de Gasteiz 
de las piezas), pretendiendo dotar de cierta homogeneidad a la superficie exterior de los muros. c) Finalmente, se destinó la lumaquela de Ajarte - caliza blanca porosa y de labra fácil procedente del Condado de Treviño- para esquinales de las torres y las jambas y arcuaciones de los accesos. Son bloques que se posicionan verticalmente en los ángulos del paramento, es decir, apoyándose unos sobre otros por medio de una de sus caras estrechas, al tiempo que muestra al exterior su superficie más extensa. En su recorrido ascendente, cada pieza alterna su disposición con sus colindantes, siguiendo el esquema de soga y tizón. Se trata de piezas labradas con cierto cuidado (tallante a $45^{\circ}$ ).

\subsubsection{Las iglesias altomedievales de Alava (Fig. 5)}

Constituyen el tipo de edificación del que tenemos una mayor cantidad de evidencias y han sido objeto de una prospección sistemática desde el Grupo de Investigación en Arqueología de la Arquitectura (SÁnCHEZ ZuFiaurre, e.p.) (Fig. 5). El esfuerzo llevado a cabo ha permitido identificar hasta 29 casos del máximo interés, cuatro de ellos exhumados mediante excavaciones arqueológicas y el resto reconocidos y "rescatados» tras una atenta «lectura» de las fábricas todavía en pie. Todas ellas han sido clasificadas en seis grupos:

Grupo 1. San Miguel de Montoria y Fase Prerrománico I de San Román de Tobillas. Edificios realizados con un aparejo de sillería reutilizada labrada con cincel de filo cóncavo. San Román de Tobillas tiene una ventana rematada en arco de herradura en el testero. Son iglesias con cabecera recta destacada.

Grupo 2. San Pedro de Urbina de Basabe, La Asunción de Samoano y San Miguel de Corro. Combinan un aparejo de mampostería en los muros con sillarejo para los esquinales y sillarejo o piezas escuadradas para los vanos. El

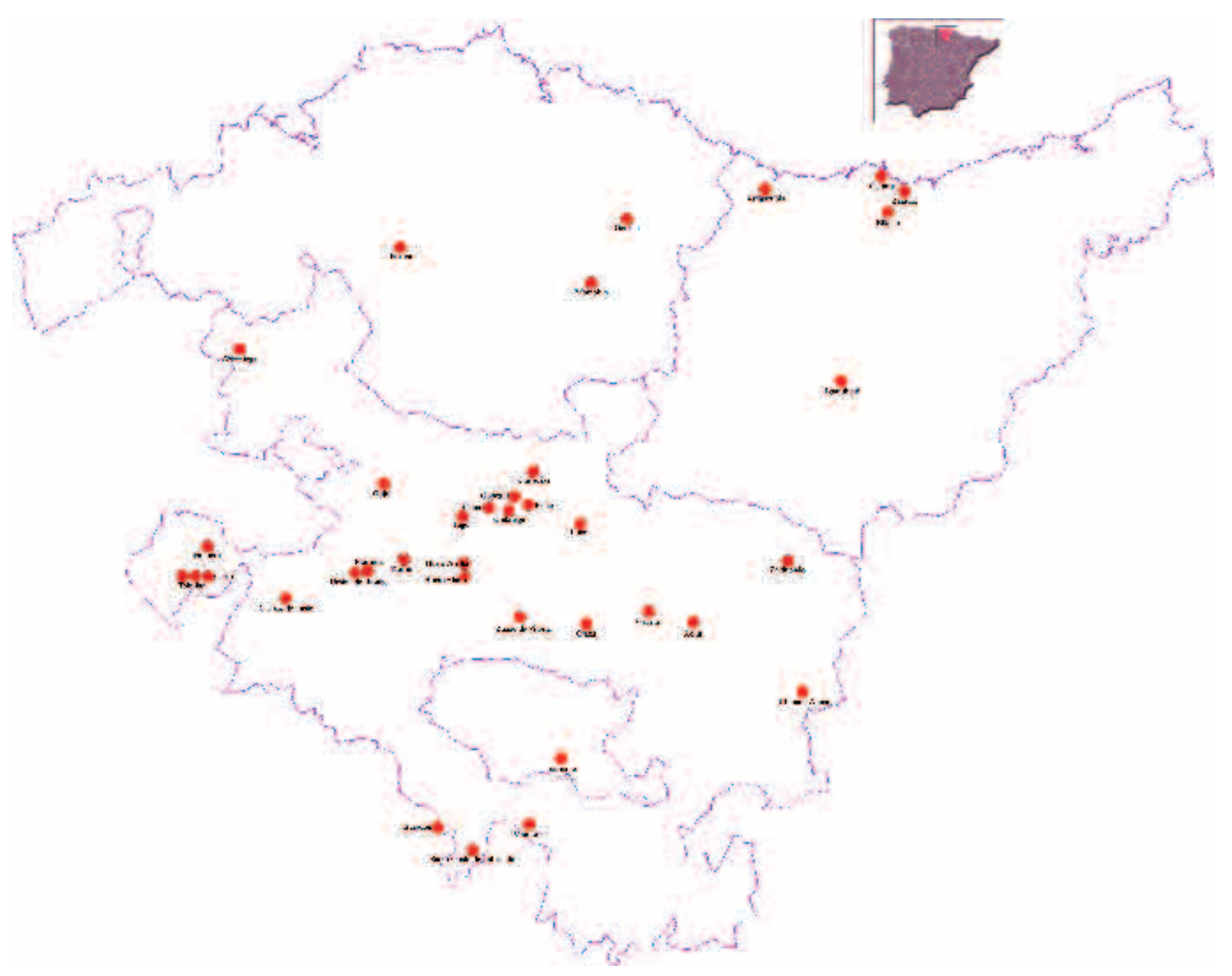

Fig. 5. Lugares mencionados en el texto, a excepción de la arquitectura rupestre 
instrumento de labra es el cincel de filo cóncavo, utilizado para el sillarejo. Las ventanas del testero (excepto en Corro, que no conserva vanos) están rematadas en arco de herradura. En este grupo podríamos incluir, también, la iglesia del yacimiento de Buradón (Salinillas de Buradón); el aparejo de los muros es de mampostería con material semielaborado, con esquinales de sillería reutilizado; como instrumentos de talla aparecen el hacha y el cincel de filo cóncavo. La cabecera de este edificio, conocido por excavación arqueológica (CEPEDA, Martínez, 1994a, 1994b; CePEDA, MarTíneZ, UnZUeTA, 1998), tiene forma de herradura. Recientemente se ha podido constatar la presencia de una fase prerrománica en la iglesia parroquial de Santa Eulalia de Atiega ${ }^{8}$, que compartiría rasgos con este grupo (esquinales de piezas escuadradas labradas a cincel de filo cóncavo, aparejo de mampostería).

Grupo 3. Fase Prerrománico II de San Román de Tobillas, Andra Mari de Ullibarri Arana y San Julián de Aistra (Zalduondo). Son obras realizadas íntegramente en sillería labrada ex novo, tanto para el muro como para los esquinales y vanos. El instrumento de labra es el cincel de filo cóncavo, excepto para Aistra donde la dureza del material exigía otro instrumental (hacha y picón). La única ventana conservada en el testero (Aistra) está rematada en arco de herradura.

Grupo 4. San Pedro de Gorostiza (Zestafe), San Martín de Eribe y San Vicente de Hueto Abajo. Son iglesias cuyo aparejo es de mampostería, pero con la peculiaridad de que tanto para los vanos como para los esquinales utilizan sepulcros monolíticos reaprovechados. No se ha podido apreciar el instrumento de labra de las piezas; sólo se conoce la cabecera de la ermita de Gorostiza, que era recta sin destacar. Los tres edificios cuentan con ménsulas al exterior, para soportar la estructura de una edificación adosada, seguramente de madera.

Grupo 5. La Asunción de Valluerca, San Andrés de Tortura, Santiago de Gujuli, San Bartolomé de Olano, La Natividad de Hueto Arriba, San Juan ante Portam Latinam de Marinda, San Martín de Jugo y San Martín de Luko. Son edificios que comparten el aparejo de mampostería, tanto para el muro como para los esquinales. El instrumento de labra es el cincel o el picón. En dos de los casos se conservan vanos o restos de ellos (Valluerca y Luko), realizados en sillería labrada con tallante. En este grupo podemos incluir también las iglesias de los yacimientos de Los Castros de Lastra y Artziniega, ya que están realizados

\footnotetext{
${ }^{8}$ Agradecemos el dato al arqueólogo responsable de la intervención y miembro del GIAA, Alberto Plata Montero.
}

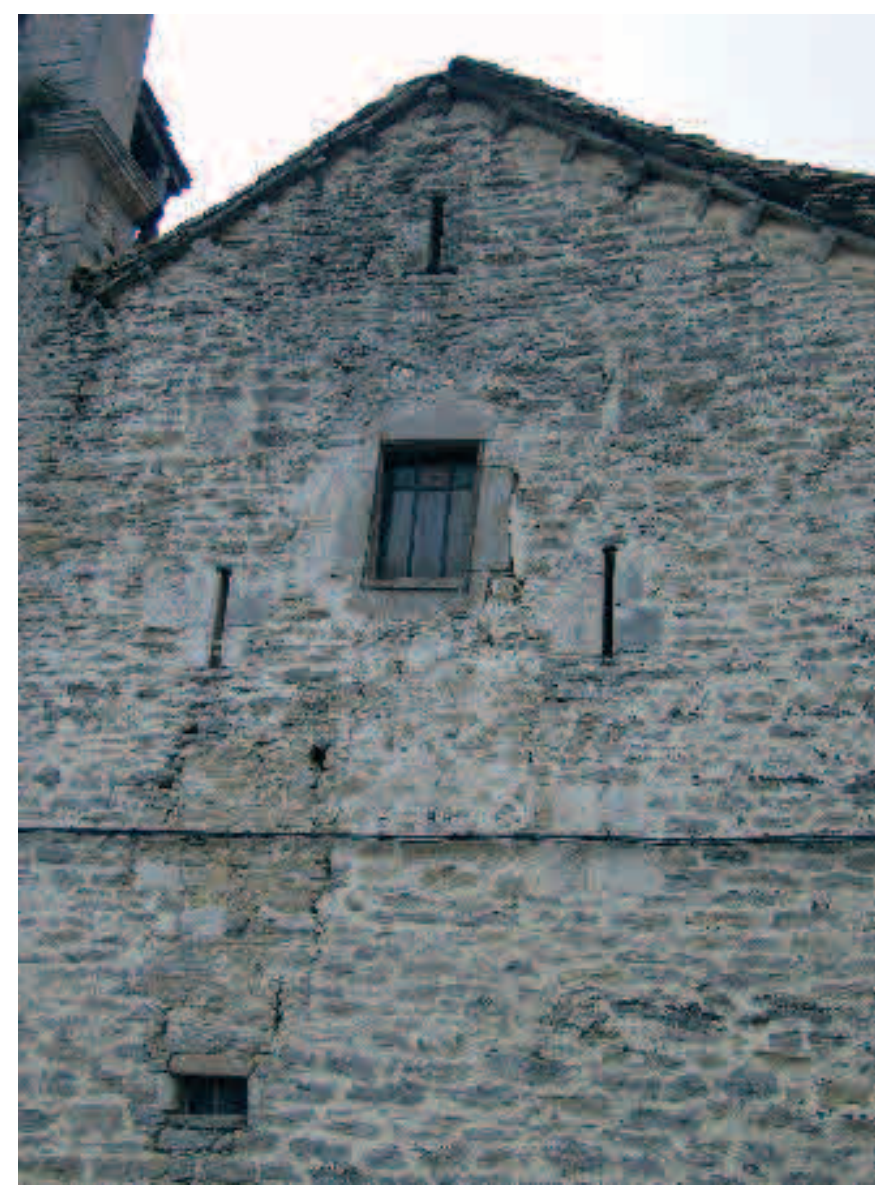

Fig. 6. Hastial occidental de la iglesia de San Martín de Gáceta

también en mampostería tanto para los muros como para los esquinales.

Grupo 6. San Juan Bautista de Acilo, La Asunción de Gopegui, San Lorenzo de Ondategi, San Martín de Otazu, San Martín de Gáceta y San Esteban de Zuazo de Vitoria. Conjunto de seis edificios con una gran homogeneidad técnica y formal, con aparejo de mampostería en los muros y de material semielaborado en los esquinales. Todos ellos presentan cuatro saeteras a los pies, articuladas en dos plantas (en algunos casos, obras posteriores han eliminado algunas de las saeteras) $)^{9}$ (Fig. 6).

\footnotetext{
9 Además de estos grupos bien definidos, contamos con otras evidencias a las que nos referiremos muy brevemente: 1. Cabría mencionar, en primer lugar, aquellas iglesias cuya existencia queda constatada estratigráficamente por formar sus restos parte de las cimentaciones románicas, pero de cuya materialidad resulta muy complicado avanzar nada mínimamente seguro. Es el caso de la iglesia de San Martín de Rivabellosa. Los restos registrados en la excavación arqueológica son únicamente cimentaciones en las que se combina el sillarejo con la mampostería irregular (AJAMIL, 2005: 197-199). Algunos elementos encontrados, como un capitel, nos permiten pensar que se trata de una obra en la que participan tanto canteros como albañiles. 2. En otros ca-
} 


\subsection{Guipúzcoa}

Guipúzcoa ha sido, de siempre, el territorio con menos evidencias altomedievales de cuantos componen la Comunidad Autónoma del País Vasco. Las investigaciones más recientes, sin embargo, están ofreciendo importantes novedades que no vienen sino a confirmar que los vacíos de información no son, generalmente, sino el reflejo de unas investigaciones que han venido priorizando unos periodos históricos en detrimento de otros. Es de esperar, por lo tanto, que durante los próximos años las diferencias informativas entre los diversos territorios vayan siendo sustituidos por un equilibrio mucho más lógico desde el punto de vista histórico. Fijémonos en algunos datos recientes relativos al territorio guipuzcoano:

\subsubsection{Caserío lgartubeiti (Ezkio-Itxaso)}

Una excavación arqueológica puso al descubierto 23 agujeros (dos de ellos de adscripción dudosa) que delimitan una superficie interior de unos $20 \mathrm{~m}^{2}$. El recinto así definido está rehundido entre 5 y $20 \mathrm{~cm}$. respecto a la superficie natural. Los agujeros son de sección circular, de 10-12 cm. de diámetro, y parecen definir un espacio separado en dos pequeñas estancias (TORRECILlA, 2003: 160-163) (Fig. 7). Los autores de la intervención proponen una cronología medieval aunque, lamentablemente, el único ante quem con el que se cuenta es la propia estructura del caserío del siglo XVI. Dadas las afinidades tipológicas de las evidencias con otras manifestaciones similares procedentes de territorio alavés, no se descarta una cronología altomedieval (Ibidem.: 168-169), o al menos anterior al siglo XIV (SANTANA, 2003: 44) y su utilización como espacio residencial (Ibidem.: 43).

sos la existencia de una iglesia anterior queda certificada únicamente por los testimonios funerarios conservados (FERNÁNDEZ BORDEGARAI, ApelláNIZ, 1996; SÁNCHEZ Zufiaurre, e.p.). 3. Y, finalmente, cabría mencionar también la presencia de algunos elementos de iglesias prerrománicas que, fuera de su contexto original, fueron reutilizadas en edificaciones posteriores a la manera que veremos también en Vizcaya: a) Iglesia de la Degollación de San Juan (Cicujano). Conserva una ventana rematada en arco de herradura en la cabecera, formando parte de la obra románica. La disposición del testero (una ventana en la parte baja rematada en herradura y una saetera en la parte alta) recuerda de manera muy marcada al testero de la iglesia de San Andrés de Astigarribia, que como se ha visto reutiliza elementos de la fase prerrománica en la construcción del siglo XII. b) Ermita de San Martín de Hermua. Conserva en la cabecera una ventana monolítica con vano rematado en arco de herradura, del tipo de la vecina de San Julián y Santa Basilisa de Aistra. Este ventanal está claramente intestado en una obra más moderna (probablemente del siglo XVIII), pero la iglesia podría estar en su emplazamiento original; la cimentación está diferenciada del resto de la obra, apreciándose una zapata en el muro oriental con una orientación ligeramente distinta a la de los alzados actuales.

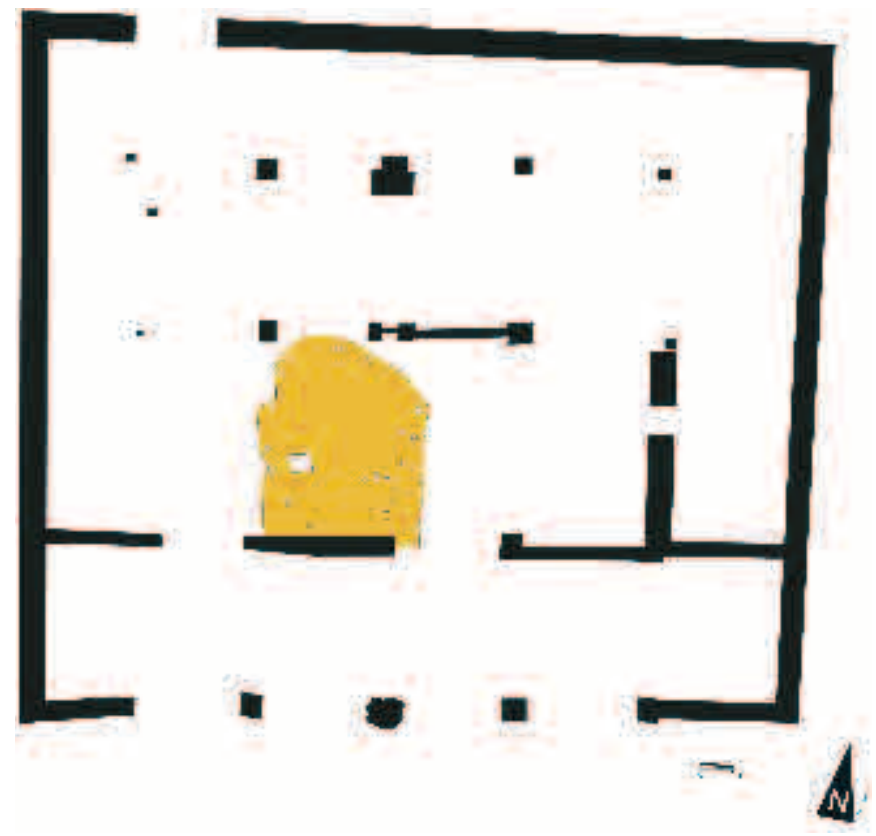

Fig. 7. Fondo de cabaña exhumado en las excavaciones arqueológicas llevadas a cabo en el caserío de Igartubeiti (TORRECILLA, 2003: 152, 159)

\subsubsection{Santa María La Real (Zarautz) (IBÁÑEZ, 2003)}

A) Templo I. Del primero de los dos templos hallados en el subsuelo de la iglesia parroquial de Zarautz se conservan cimentaciones de muros de $60 \mathrm{~cm}$. de grosor medio, realizados en mampostería caliza y arenisca, con muy escasa argamasa. Las dimensiones mínimas de la planta son de 6,72 $\mathrm{m}$. de ancho de la cabecera por 7,52 m. de longitud del muro norte. Los investigadores le asignan una cronología del siglo IX o primera mitad del $x$ y proponen, a modo de hipótesis, que pudo tratarse de una iglesia con alzados de madera sobre zócalo de piedra (Ibidem: 24-25). B) Templo II: La excavación arqueológica (Ibidem: 25-26) permitió reconocer, con posterioridad a la amortización de la primera iglesia, un segundo edificio de planta rectangular y testero recto. Sus dimensiones son de 4,73 m. de ancho interior y una longitud mínima de $8,3 \mathrm{~m}$. Sólo se localizaron los paños este, norte y sur (se propone que su planta fuera la misma que la construcción registrada en el subsuelo de San Pedro de Elkano, con una longitud de 10,4 m.). Con muros de mampostería de $72 \mathrm{~cm}$. de grosor, los autores de la excavación dudan respecto al tipo de alzado que pudo tener la iglesia, sugiriendo la posibilidad de que fuera también madera por la casi nula cimentación que presenta. Este edificio sufrirá una serie de reformas antes de su arrasamiento, en especial en la zona del presbiterio y el altar. La cronología propuesta para su construcción es coetánea a la segunda fase de la necrópolis del yacimiento, fechada entre los siglos X y XII. Sigue en uso hasta el siglo XIII, cuan- 
do Zarautz se convierte en villa y se construye la iglesia románica que arrasa definitivamente las mencionadas construcciones $^{10}$.

\subsubsection{Iglesia de San Andrés de Astigarribia (Mutriku)}

A partir de la década de 1970, los trabajos de I. Barandiarán (1971) llevaron a pensar que el edificio actual tenía su origen en el siglo XI, en especial gracias a la presencia de una ventana rematada en arco de herradura en la cabecera. Una importante capa de enlucidos en toda la fábrica impedía tener una correcta visión de los alzados de la construcción, algo que limitaba necesariamente la fiabilidad de la adscripción cronológica. En años recientes fue posible realizar una nueva excavación de partes importantes del subsuelo de la iglesia (Pérez Centeno, Pí́, 2001, 2002, 2003), así como un análisis estratigráfico completo de los alzados del conjunto (SÁNCHEZ ZuFIAURRE, 2003).

En esta ocasión se pudo comprobar que las piezas de la ventana estaban reutilizadas fuera de su emplazamiento original, a pesar de que la primitiva iglesia estuviera, con toda probabilidad, en el mismo emplazamiento. Aunque podemos deducir sus dimensiones ${ }^{11}$ no conocemos, por desgracia, las características técnicas de los muros. El tipo de labra empleado en las piezas de las ventanas, sin embargo, — cincel de filo cóncavo- permite poner en relación esta primera iglesia con un grupo de edificios alaveses cuyas cronologías se sitúan entre los siglos IX y X (SÁNCHEZ ZUFIAURRE, e.p.). Esto retrotraería al menos un siglo la cronología propuesta para la primera fase de Astigarribia.

\subsubsection{San Pedro de Elkano}

Su excavación en el año 1988 (ZALDUA, 1989) permitió conocer - a pesar de detectarse únicamente muros arrasados y cimentaciones excavadas en la roca - la planta de una iglesia anterior a la actual, de testero recto con unas dimensiones de $10,4 \times 4,73 \mathrm{~m}$. Aunque en su momento se la

\footnotetext{
10 Existen dudas respecto a esta iglesia, expuestas ya por los autores de la intervención, que consideran que la escasez de cimentación es evidencia de unos alzados poco consistentes. Sin embargo, creemos que hay argumentos para pensar en unos alzados enteramente de piedra. En primer lugar, la cronología propuesta para esta iglesia, perdurando hasta el siglo XIII, indica que se trata de una edificación de cierta entidad que le permite afrontar el paso del tiempo; incluso se realizan reformas en los muros, siempre en material lítico, lo que nos indicaría el tipo de material predominante de que se trata. Por último, el hecho de que se conserven escasas hiladas de la cimentación no significa que fueran las únicas hiladas de piedra existentes; de hecho, las obras del Templo III arrasan con lo anterior, por lo que desconocemos las dimensiones originales de los cimientos. El aspecto de los muros, así como la unión de las piezas con argamasa de cal, nos llevan a pensar en unos alzados de material pétreo.

11 Cfr. argumentos en SÁnchez Zufiaurre, 2003.
}

consideró como un edificio de los siglos XII-XIII, A. Ibáñez (2003: 13) ha adelantado recientemente su cronología llevándola al mismo horizonte que el del templo II de Santa María la Real de Zarautz. Resulta muy interesante esta ermita, ya que está formada por muros de piedra y tiene dos «ampliaciones» (al menos así las interpreta el autor), o cuerpos adosados; el primero de ellos consiste en «cuatro agujeros circulares excavados en la roca natural, de dimensiones similares, que configuran una hilera más o menos paralela a la línea que describiría el antiguo muro norte. Suponemos que estos agujeros en su origen, acogerían la estructura de basa de unos postes o pies derechos, que en conjunto, nos inclinamos a pensar, formaban un cuerpo a modo de pórtico que se le adosaba a la primitiva ermita por lo menos por el norte (...). Cubriendo parcialmente dos de estos agujeros, aparecieron restos de la cimentación de otro muro que dibujaba un espacio rectangular que también se le adosó a la planta original por el norte» (ZALDUA, 1989). Creemos que, en realidad, nos encontramos con las evidencias de una edificación adosada a la iglesia realizada en madera; por su ubicación podemos ponerla en relación con las estructuras adosadas a las iglesias alavesas del grupo 4, cuyas funciones serían seguramente de almacenamiento. Lo que resulta del máximo interés, ya que supone un nexo entre las tradiciones de ambos territorios.

\subsubsection{San Salvador de Getaria}

Las excavaciones arqueológicas (GEREÑU, 2001) permitieron identificar dos templos anteriores al actual, en una secuencia similar a la de Santa María la Real de Zarautz aunque algo más tardía. La primera iglesia pudo ser reconocida sólo parcialmente, con una superficie aproximada de $22 \mathrm{~m}^{2}$ y una cronología entre los siglos XI y XII; las fechas se obtuvieron por medio de la datación radiocarbónica de unos enterramientos en cista de laja asociados. El templo 2 cubre al anterior, perteneciendo al momento fundacional de la villa, por lo que quedaría al margen de nuestro ámbito cronológico (IBÁÑEZ, 2003: 13). Lamentablemente, más allá de saber que se trata de un edificio de piedra, desconocemos las características técnicas de los alzados del primero de los templos.

\subsection{Vizcaya}

Hasta el momento no contamos con evidencias directas de arquitectura íntegramente lígnea o arquitectura mixta en territorio vizcaíno; sin embargo, algunas de las iglesias en las que se han documentado restos altomedievales construidos en piedra parecen haber tenido al menos parte de sus alzados de madera (GARCía CAMINO, 2002: 202), como por ejemplo Momoitio (Ibidem: 118). 
Las evidencias directas de centros de culto edificados en piedra en Vizcaya son realmente limitadas, si bien algo más numerosas que las guipuzcoanas (o al menos más seguras). Todas ellas, sin embargo, corresponden a elementos registrados en excavaciones arqueológicas; no existen (o al menos no se han identificado) iglesias altomedievales conservadas en pie. Los únicos restos seguros de muros edificados en piedra son los que se hallaron en las excavaciones de las ermitas de San Martín de Fínaga (Basauri) y San Juan de Momoitio (Garai). El resto de evidencias pertenecen a elementos aislados o empotrados en construcciones más recientes, cuya cronología es claramente altomedieval; la mayoría de estos elementos son ventanas monolíticas, aunque también se conservan sillares con inscripciones o tenantes de altar. No incluimos todos los restos considerados altomedievales, como por ejemplo las necrópolis, ya que si bien están evidenciando la presencia de una iglesia, desconocemos el tipo de técnica constructiva empleada.

Las iglesias en las que se conservan ventanas monolíticas de tradición mozárabe o asturiana ${ }^{12}$, así como otros testimonios arquitectónicos de siglos altomedievales ${ }^{13}$ han sido bien recogidos y estudiados por I. García Camino (2002).

En todos los casos vizcaínos podemos estar suficientemente seguros como para pensar en una estructura de piedra que acogiera a los elementos altomedievales conservados. Desconocemos, lamentablemente, qué técnica constructiva fue empleada en cada caso. La información

12 Ermita de Santa Lucía de Gerrika (Arbatzegi-Gerrikaitz); Ermita de San Pedro de Arta (Markina-Xemein); Ermita de San Esteban de Berreño (Arbatzegi-Gerrikaitz); Ermita de San Lorenzo de Lamikiz (Mendata); Ermita de San Lorenzo de Islas (Arteaga); Iglesia de Santa María de Axpe (Busturia); Caserío Urrieldu, levantado sobre la ermita de San Miguel de Gorozika (Muxika); Ermita de Santa María Magdalena de Iona (Mungia); Ermita de San Salvador de Zarandoa (Larrabetzu); Ermita de la Santa Cruz (yacimiento de Memaia I, Santa Cruz, Elorrio; además de la ventana se documentó un sillar con una inscripción datada en el siglo X); Ermita de Andra Mari de Goiuria (Iurreta); Monasterio de San Martín de Amatsa (Iurreta); Ermita de San Pedro de Abrisketa (Arrigorriaga); Ermita de San Miguel de Elejabeitia (Artea, Castillo Elejabeitia; además de la ventana, conserva una estela prerrománica); Ermita de San Antonio de Barañano (Zeberio); Iglesia de San Adrián de Argiñano (Zeberio).

${ }^{13}$ En la Colegiata de Zenarruza (Markina-Xemein) se conserva, reaprovechado en los muros de la obra del siglo XIII, un sillar prerrománico; En la Ermita de San Bartolomé de Miota (Elorrio) se recuperó un interesante tenante de altar cuadrangular, además de sepulcros y lápidas; En el yacimiento de Memaia II (Santa Marina, Elorrio), se rescató una inscripción de suma importancia por su cronología y advocaciones (AZKARATE, 1986: 347-355): bloque de arenisca con las advocaciones de Santa Marina, Santa Cruz y San Acisclo, fechado en el siglo X; La Ermita de San Lorenzo de Otzerimendi (Zeanuri) conserva un tenante de altar y un bloque de arenisca con dibujos que estaría entre los siglos IX y XI; En la ermita de Santa Lucía de Alzusta (Zeanuri) se encontró un tenante de altar con lipsanoteca. que aportan las dos iglesias que conservan restos de sus cimentaciones de piedra tampoco es muy elocuente, aunque nos permite establecer correlaciones con ejemplares de territorios vecinos.

\subsubsection{Ermita de San Martín de Finaga (Basauri)}

Iglesia rehecha en el siglo XVIII; en la excavación de su interior se detectó la cimentación de un edificio anterior «de planta rectangular de 17 metros cuadrados rematado en cabecera diferenciada, estrecha y también rectangular, aunque de menores dimensiones (2,65 metros cuadrados)» (GARCÍA Camino, 2002: 63). Sus muros son de mampostería asentados a seco, de 40 ó $60 \mathrm{~cm}$ de ancho. La cabecera es un añadido posterior a la nave. Al norte se adosa una pequeña estructura abierta, probablemente porticada, de $c a$. 2,25 metros cuadrados. Cronología: 1) Fase Bajo Imperial (siglos IV-V); construcción de 17 metros cuadrados útiles, mampostería a seco, con una necrópolis alrededor. 2) Fase Tardo Antigua (siglos VI-VIII); añadido de la cabecera rectangular, de 1,9 por 1,3 m., que acogía un tenante de altar. Se estrecha el ingreso a la cabecera por medio de dos basas en la embocadura, que sustentarían pies derechos. Es probable que se ampliara la nave hacia el oeste. La técnica constructiva es similar a la de la fase anterior. 3) Fase Altomedieval (siglos IX-X); añadido de una estructura al norte, a modo de porche o zaguán, de escasa entidad. A mediados del siglo XI o en el XII el estado de ruina del edificio era total, demoliéndose parte de sus muros.

\subsubsection{Ermita de San Juan de Momoitio (Garai) (GARCía CAMINo, 2002: 78-119)}

Iglesia reconstruida en el siglo XVI. Las excavaciones arqueológicas recuperaron la planta de una iglesia anterior de mampostería que probablemente alternaba sus alzados con madera, construida en torno a finales del siglo VIII o inicios del IX. Esta fase del yacimiento, con su necrópolis asociada, duró hasta el siglo XI. A finales de dicha centuria comenzaría el declive y abandono en favor de otro centro de culto. La iglesia altomedieval era un edificio de planta rectangular de 4,20 por $3,10 \mathrm{~m}$. y superficie de $13 \mathrm{~m}^{2}$, con el eje mayor orientado de norte a sur. El paramento era «de doble muro de mampostería con 45 cts. de relleno de ripio, trabado con mortero de arena y cal»; el grosor era de $85 \mathrm{~cm}$. en el cimiento. La cubierta era de madera sobre pies derechos, encontrándose tres apoyos (dos en los muros y uno en el centro del edificio; «no sería aboveda$\mathrm{da}$, sino una ligera techumbre recubierta de materiales vegetales o de tablillas de madera, como podría deducirse de la ausencia de lajas planas o de tejas en el área de la excavación» (Ibidem: 83). 


\subsubsection{Ermita de Santa Lucía (Gerrika-Arbatzegi) (García Camino, NeIRA ZUbIeta, e.p.)}

Una intervención arqueológica reciente ha permitido registrar un pequeño templo de planta rectangular, que combinaría en su estructura muros de piedra y madera. El extremo oriental de la iglesia era de piedra, habiéndose conservado los restos del cierre sur y la zanja de robo del muro norte. El muro de piedra tiene un grosor de $83 \mathrm{~cm}$., con una longitud de $216 \mathrm{~cm}$. Hacia el oeste la estructura sería de madera, asentada en agujeros de poste y en bases de piedra. Este edificio tiene una cronología de los siglos X-XI.

\section{LOS MATERIALES, LAS TECNICAS Y SU CRONOLOGIA}

«Solidez, utilidad, belleza». De esta manera sintetizaba Vitrubio los tres principios que deben regir la arquitectura. Tres conceptos capaces de reflejar aspectos vitales de una sociedad. Sus recursos para proveerse de materias primas, extraerlas, transformarlas, transportarlas; su capacidad para aparejar unos materiales, levantando unas construcciones que superen los retos de la estática y la mecánica; su organización social, política y religiosa necesitada de articular unos espacios de funcionalidades y significados simbólicos diversos (AZKARATE, 2000). Es por ello, "por la suma de hechos que es necesario que se conjuguen para su materialización» por lo que la arquitectura se ha considerado con razón como «la máxima expresión de lo que entendemos por cultura material» (LATORRE, 1996: 108).

Saben mucho de todo ello quienes, desde la antropología y la arqueología, vienen investigando desde hace tiempo sobre el «saper fare» empírico como criterio que guió la generalidad de los procesos productivos conocidos en el mundo preindustrial (LEROI-GOURHAN, 1989; BIANCHI, 1996: 53-56; SÁNCHEZ ZufiaurRE, e.p.). Los párrafos que siguen son deudores de estos trabajos y, especialmente, de aquellos desarrollados por el Istituto di Storia della Cultura Materiale (Génova), bajo la dirección de T. Mannoni.

En esta ocasión nos fijaremos en los aspectos relativos a los conocimientos y medios disponibles en las comunidades aldeanas y a su progresiva transformación en función del contacto con constructores especializados. Para ello nos interesa recordar algunos conceptos básicos.

En el ámbito preindustrial dominado por el «saper fare», las comunidades humanas de tamaño pequeño o medio (como el de las aldeas altomedievales) eran capaces de fabricar distintos productos a partir de una serie de conocimientos regulados por una determinada secuencia de acciones. Este conjunto de conocimientos que regulan la vida técnica dentro del grupo, es lo que conocemos como ambiente técnico. De él participan casi todos los miembros de la comunidad y de él se sirven para la satisfacción de sus necesidades.
Este contexto no era inmutable. La interacción con conocimientos del exterior, así como la reelaboración interna dentro del propio grupo, producía una serie de cambios en el ambiente técnico. El proceso resultante de esa interacción interior-exterior es lo que se conoce como tendencia técnica. Esa expresión, en definitiva, define el grado de evolución de un estímulo externo dentro de un ambiente técnico, una vez que aquel es reinterpretado por la comunidad.

Los gestos propios de cada grupo forman parte de una cadena operativa en la que todas las operaciones se encadenan en el espacio y en el tiempo, quedando cada uno de estos pasos fijado en la memoria histórica del colectivo. Los cambios operados en un momento determinado por la relación con grupos de constructores especializados hacen que la cadena de acciones asumida por la comunidad para la elaboración de un artefacto cambie en alguno de sus puntos. Estos cambios se explican gracias al concepto de $v a$ riante, ya utilizado por los especialistas en cerámica. Es un concepto que permite definir el grado de personalización de una base técnica común. La variante técnica puede comprender tanto los cambios que se operan en las comunidades locales gracias al contacto con los constructores especializados, como los cambios operados en la cadena operativa de un grupo de constructores especializados una vez que dicha cadena es asumida a nivel local.

Para entender mejor estos conceptos podemos recurrir a algunos ejemplos. En una comunidad en la que la arquitectura se ejecuta en madera, colocando postes directamente en el terreno, la cadena operativa incluye la extracción de la madera, su tratamiento y su colocación, así como la elaboración de los entramados de ramas y barro para los muros. Sea tanto por reelaboración propia como por contacto con otros ambientes, en un momento determinado se produce una innovación que lleva a apoyar los postes de madera sobre zócalos de piedra. La aparición de esa mejora técnica supone una variante dentro del ambiente técnico local, ya que el resto de la cadena operativa se mantiene.

Hay otras ocasiones en las que los cambios en el ambiente técnico se producen claramente por contacto con grupos técnicos más especializados, no siendo originados en el seno de la comunidad. Es el caso, por ejemplo, de las ventanas altomedievales (monolíticas o no) que aparecen en numerosas iglesias de nuestro entorno. Estas ventanas aparecen en algunos edificios en los que toda la fábrica se realiza por mano de obra especializada, con técnicas de cantería (Aistra, por ejemplo) o albañilería, pero con medios técnicos propios del grupo técnico de los constructores (Samiano es una de ellas). Sin embargo, en otros ejemplos aparecen ventanas monolíticas en contextos en los que el muro refleja la actuación de mano de obra local no especializada. 
Parece claro, en esos casos, que estamos ante una variante dentro del ambiente técnico local.

En esta ocasión vamos a fijarnos en la arquitectura en piedra, mucho más abundante y explícita que otras formas constructivas. Para su estudio hemos de tomar en cuenta, fundamentalmente dos ciclos productivos: el de la piedra y el de la cal.

\subsection{El ciclo de la piedra}

Al igual que ocurre en otros ciclos productivos, también en éste se acostumbra a distinguir la fase de obtención del material (en unos casos mediante la reutilización de componentes constructivos procedentes de edificaciones anteriores; en otros recurriendo a la recolección de elementos próximos o inmediatos al lugar del emplazamiento de la nueva edificación; o, finalmente, acudiendo a canteras para la extracción del material constructivo) de aquella otra fase de tratamiento $y$ puesta en obra (unas veces sin tratamiento alguno -es el caso de los materiales de recolección-; otras veces con un tratamiento también mínimo — por extraer las piezas siguiendo las líneas de diaclasas y conseguir, sin excesivo esfuerzo, piezas relativamente regulares-; en un tercer caso escuadrando someramente las futuras piezas hasta alcanzar un material semielaborado; y, finalmente, con un grado de sofisticación técnica suficiente como para conseguir materiales bien escuadrados ${ }^{14}$ ) (Fig. 8).

${ }_{14}$ No siempre hablamos con propiedad cuando nos referimos, por ejemplo, a la sillería. En ocasiones usamos este concepto desde criterios formales cuando deberíamos hacerlo desde criterios estrictamente tecnológicos, como se propone desde la antropología de la producción y defienden autores tan conocidos como Bessac o el propio Mannoni. Un sillar es, formalmente, un paralelepípedo rectangular, de manera que muchas piedras colocadas en esquinales por ejemplo, pueden parecernos sillares. $Y$ así los registramos. Tecnológicamente, sin embargo, un sillar debe cumplir con dos reglas fundamentales. En primer lugar, cada cara debe constituir un plano rectangular. Para ello se necesita el cincel, la maceta o martillo, una escuadra y al menos una regla para trazar los contornos y conseguir el cuarto ángulo del plano, una vez elegidos los tres primeros. Hacen falta, además, otros instrumentos (punzón, gradina, martelina) para tallar y alisar la parte central de las caras. En segundo lugar, cada superficie debe ser perfectamente perpendicular con las cuatro caras adyacentes y ello se obtiene con el uso de la escuadra. Todo ello tiene su complejidad y requiere de una especialización considerable y un tiempo de ejecución no desdeñable (de 6 a 8 horas para un sillar de tamaño medio en un material de dureza también media).El cumplimiento de estas dos reglas nos remite al ámbito especifico del cantero. El albañil puede tratar de imitar al cantero. Sin embargo, no siendo capaz de producir los bloques perfectamente escuadrados, obtiene resultados aparentemente similares con ángulos más o menos rectos entre las tres dimensiones espaciales de cada producto final. A diferencia, sin embargo, de los interfaces entre los sillares del cantero, bien escuadrados y con tantos puntos de contacto que pueden no necesitar de argamasa alguna, los sillares pseudoescuadrados del albañil presentarán superficies aproximadas, por lo que se obtienen juntas bastante anchas, un número menor de contactos entre los distintos elementos y la necesidad, consecuentemente, de mayor cantidad de argamasa (MANNONI, 1997).
Como nos dice Mannoni, la distinción fundamental que debe hacerse a la hora de estudiar los muros de piedra es la que existe entre «los muros de albañil», $y$ «los muros de cantero». O, quizá mejor, entre las «técnicas de albañil» y "las técnicas de cantero», "dos formas de construir que tienen en común menos de lo que podemos imaginar» (MANNONI, 1997).

\subsubsection{Edificios con técnica de cantería}

Son pocas las construcciones realizadas íntegramente con técnicas de cantero, y menos aún las que se elaboran a partir de materiales labrados ex novo. Aquí debemos establecer una diferencia entre ambos, ya que este aspecto nos puede indicar importantes aspectos relacionados con los medios disponibles.

a) Edificios realizados con sillería a base de materiales reaprovechados: aparece en las iglesias de San Román de Tobillas (fase Prerrománico I) y San Miguel de Montoria; en ambos casos se trata de la reutilización de sillares provenientes de obras anteriores (seguramente romanos), retallados a cincel de filo cóncavo para su nuevo emplazamiento. La cronología de estas iglesias es del siglo IX.

b) Edificios realizados con sillería labrada ex novo: se limita a las iglesias de San Román de Tobillas (fase Prerrománico II), la ermita de Andra Mari de Ullibarri-Arana y la ermita de San Julián y Santa Basilisa de Aistra. Se trata de sillares con un muy buen acabado, si bien sus caras verticales son oblicuas, lo que indica que las piezas se labraban in situ; el instrumento empleado para la labra es el cincel de filo cóncavo. Su cronología es del siglo X.

\subsubsection{Edificios en los que se combina técnica de cantería y técnica de albañil}

Se trata de una serie de edificios en los que el aparejo de los muros es de mampostería, es decir, están ejecutados con técnica de albañil, pero los esquinales y vanos se realizan con técnicas de cantería. En este apartado encontramos dos modelos, diferenciados por el tipo de instrumento empleado en la labra de las piezas de vanos y esquinas. Los más antiguos usan el cincel de filo cóncavo, y los más modernos el tallante.

a) Entre los primeros (aquellos que usan el cincel de filo cóncavo) nos referimos a las iglesias de San Pedro de Urbina de Basabe, La Asunción de Samiano, San Miguel de Corro, la fase primitiva de San Andrés de Astigarribia, la iglesia de Santa Eulalia de Atiega y la iglesia — descubierta en excavación arqueológica- de Buradón. En los cinco primeros casos las partes realizadas por canteros están labradas con un cincel de filo cóncavo, empleando piedras más blandas que las utilizadas en la mampostería del muro. Tres 


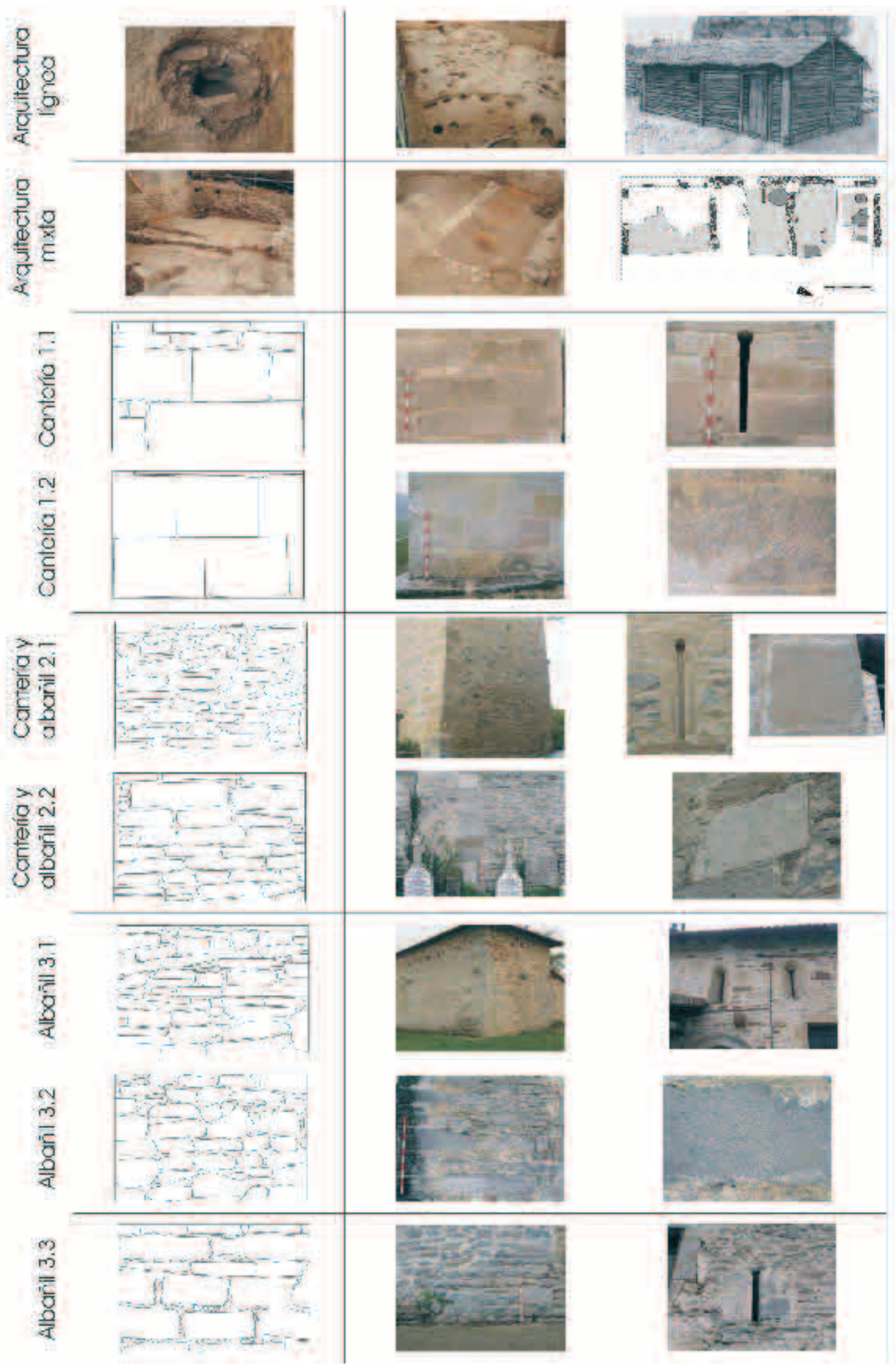

Fig. 8. Técnicas analizadas en el texto, con sus aparejos y ejemplos correspondientes 
de las iglesias (Urbina de Basabe, Montoria y Castros de Lastra) tenían en su cabecera una ventana rematada en arco de herradura. Este hecho las pone en relación con la fase Prerrománico I de Tobillas y la ermita de Aistra (que tiene un vano similar labrado en una sola pieza). Buradón, en la que no se conservan vanos, tiene la cabecera en planta de herradura. Estos datos, sumados a la utilización del cincel de filo cóncavo, permiten suponer para estas iglesias unas cronologías similares a las ejecutadas íntegramente en cantería, es decir, entre los siglos IX y X.

b) El segundo conjunto está compuesto por cinco edificios, que en realidad pertenecen a dos grupos diferenciados; La Asunción de Valluerca y San Martín de Luko tienen aparejo de mampostería en los muros, pero los vanos realizados en sillería labrada a tallante. Los tres edificios restantes (San Martín de Gáceta, San Martín de Otazu y San Esteban de Zuazo de Vitoria) serán analizados aparte, al pertenecer a una serie de iglesias construidas prácticamente en serie que requieren un tratamiento individualizado. La cronología de Valluerca puede estar entre los siglos X y XI; Luko pudo haber sido construida en torno a mediados del siglo XI.

\subsubsection{Edificios con técnica de albañil (Fig. 9)}

El resto de las iglesias de nuestro estudio están construidas con técnicas de albañil, si bien algunas de ellas cuentan con características que nos permiten individualizarlas. a) Edificios de mampostería con esquinales y vanos de materiales reaprovechados. Nos referimos a tres iglesias en las que las esquinas y vanos se realizan con sepulcros monolíticos reutilizados: ermita de San Pedro de Gorostiza (Zestafe), San Martín de Eribe y San Vicente de Hueto Abajo. Se trata de edificios construidos entre los siglos X y XII, probablemente con una mayor incidencia en el XI; Eribe tiene una argamasa idéntica a la de la iglesia de Gujuli; este hecho, junto con otras evidencias, nos llevan a pensar en la aparición de un centro de producción de cal, cuya cronología sería muy probablemente del siglo XI.

b) Edificios ejecutados con técnica de albañil sin materiales reutilizados. Se trata de las iglesias de San Andrés de Tortura, Santiago de Gujuli, San Bartolomé de Olano, La Natividad de Hueto Arriba, San Juan ante Portam Latinam de Marinda, San Martín de Jugo y los restos prerrománicos — descubiertos en excavación arqueológica- del santuario de la Encina (Artziniega), las iglesias de Santa María La Real de Zarautz, San Pedro de Elkano, San Salvador de Getaria y las ermitas del Santo Cristo de Labastida, San Martín de Finaga (Basauri) y San Juan de Momoitio (Garai). Estos edificios en conjunto ostentan una cronología que va de los siglos IX al XII; sin embargo, hay algunas de estas iglesias que pueden ser encuadradas con ciertas garantías en un rango cronológico más ajustado: la Encina y Finaga en los siglos IX-X, Momoitio a finales del siglo VIII o siglo IX y Olano, Gujuli y Marinda a lo largo del siglo XI.

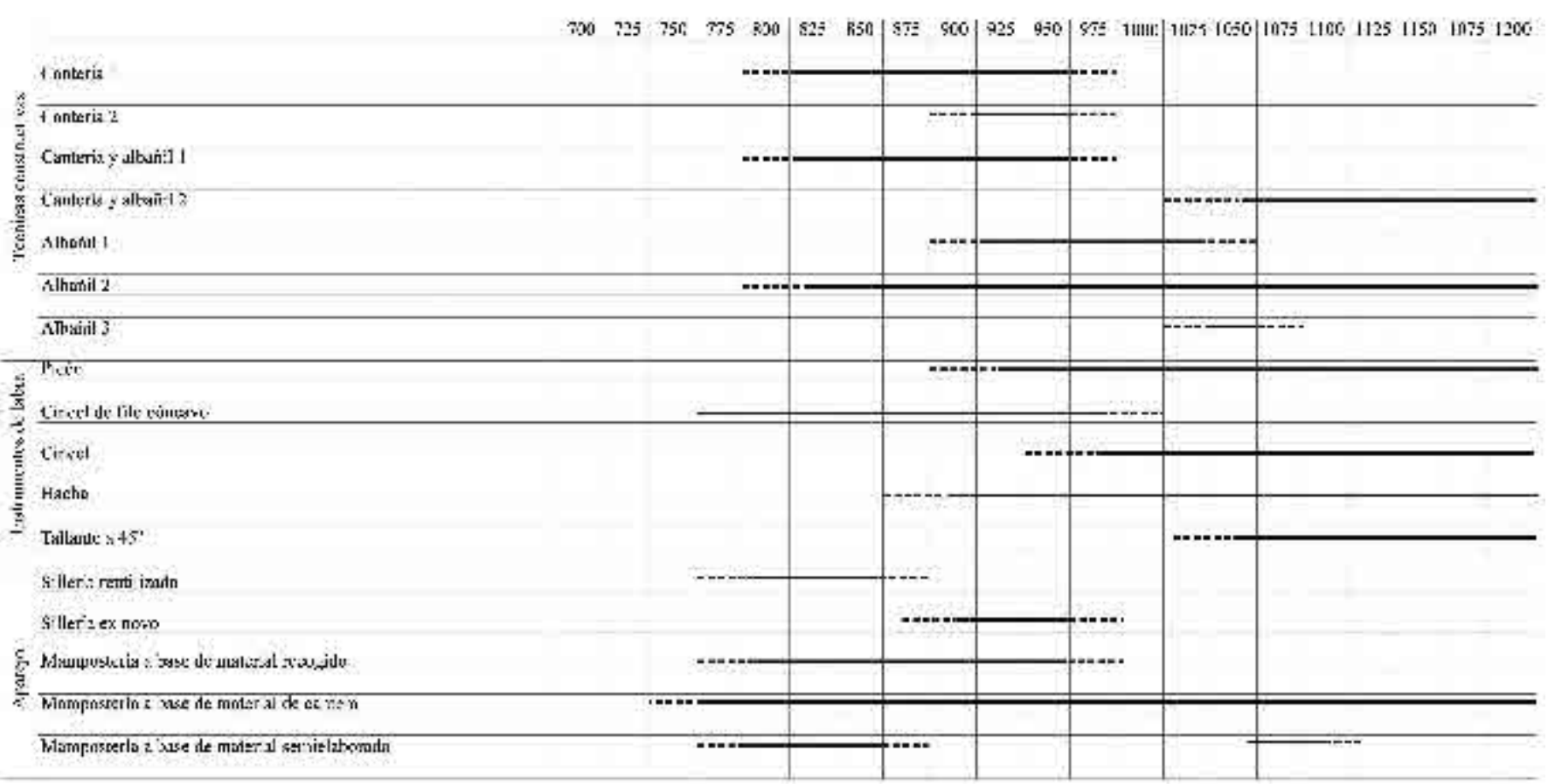

Fig. 9. Tabla cronotipológica de las técnicas mencionadas en el texto 
Es altamente probable que la gran cantidad de edificios vizcaínos en los que aparecen ventanas monolíticas estuvieran construidos según este tipo de técnica; los vanos estarían embutidos en la fábrica de mampostería, siendo el único elemento labrado del conjunto; la obra sería por lo tanto de albañil, a pesar de contar con algún instrumental de cantería.

c) Hay una última clase de edificios formada por seis de las iglesias reconocidas en Álava como anteriores al románico que, si bien por sus características técnicas se encuadran dentro de las técnicas de albañilería, el hecho de que estén realizados en serie nos indica que fueron realizados por constructores especializados en un corto período de tiempo. Se trata de las iglesias del Grupo 6: San Juan Bautista de Acilu, La Asunción de Gopegui, San Lorenzo de Ondategi, San Martín de Otazu, San Martín de Gáceta y San Esteban de Zuazo de Vitoria. Los aparejos presentes en estos edificios son de dos tipos: en tres iglesias (Ondategi, Gáceta y Zuazo de Vitoria) se trata de mampostería a base de material nuevo extraído por capas naturales (spaccatura); en Acilu y Ondategi encontramos mampostería a base de material semielaborado (sbozzatura); en la iglesia de Gopegui se combinan ambos tipos de aparejo. Los esquinales, en todos los casos, están realizados a base de material semielaborado. El instrumento de labra es siempre el picón, excepto en Acilu donde no es posible ver las marcas de talla. La técnica constructiva es, para todos los edificios, de albañil. Todas las iglesias cuentan con cuatro saeteras abiertas a los pies (en algún caso faltan algunas, eliminadas por obras posteriores); en tres de los casos (Otazu, Gáceta y Zuazo de Vitoria) las piezas que forman las ventanas están elaboradas con técnicas de cantería, labradas con tallante. La cronología de esta serie de iglesias es de la segunda mitad del siglo XI.

\subsection{El ciclo de la cal}

La clasificación que hemos realizado hasta ahora está fundada únicamente en los criterios técnicos derivados de las características de la obra en piedra; el contrapunto necesario a dicha clasificación deberá ser el estudio de las argamasas, sin las cuales no tenemos construcción en piedra.

Para ello contamos con análisis de morteros de 14 igle$\operatorname{sias}^{15}$ (todas ellas alavesas), encuadradas en todas las variantes técnicas estudiadas. En el estudio de la cal se analiza la composición de los áridos y el aglomerante, procurando establecer su origen y la técnica de ejecución, lo que revelará el nivel técnico de sus productores. En todos los casos

15 Estudio realizado por la geóloga Blanca Guarás. estudiados se trata de morteros realizados con cal de muy buena calidad, sin intrusiones y con un apagado bien ejecutado, algo que señala que su origen no está en producciones domésticas sino que son obra de personal especializado.

Se ha podido establecer que para los áridos se emplean siempre arenas cuaternarias procedentes de cauces de ríos, con siete puntos de obtención del material que pueden ser agrupados en dos grandes apartados: un grupo en el que las arenas se obtienen del cauce más cercano al emplazamiento de la iglesia, y un segundo grupo en el que la obtención de los áridos se realiza en una zona de extracción común. En este segundo caso la zona de extracción es el cauce del río Bayas, al norte del diapiro de Murguía; a este grupo pertenecen 7 de las iglesias en las que se han analizado los morteros, cantidad realmente significativa $(50 \%$ del total de la muestra). Son las iglesias de Gujuli, Marinda, Olano, Ondategi, Eribe, Gorostiza y Luko.

Dos de estas iglesias no sólo comparten un origen común para la extracción del material, sino que la identidad entre sus argamasas es tal que sólo puede explicarse si fueron hechas a la vez; se trata de las iglesias de Eribe y Gujuli, que como vimos recurren a elementos técnicos diferenciados para la ejecución de los muros (en Eribe se reutilizan sepulcros para las esquinas y los vanos).

\subsection{Los constructores}

Cabe preguntarse en este punto si estamos ante iglesias realizadas por las propias comunidades locales o si, por el contrario, en su erección tuvieron que ver comitentes capaces de sufragar los elevados costes de constructores especializados. Aunque la información disponible no puede ser del todo concluyente, creemos que existen evidencias suficientes para defender la segunda de las posibilidades. En las líneas que siguen trataremos de exponer, muy brevemente, los criterios que nos llevan a pensar que los conocimientos reflejados por la mayoría de las iglesias de piedra reconocidas no es el propio de los habitantes de las aldeas.

—Siglos VIII-X d.C. Allí donde hemos podido reconocer las características de las construcciones domésticas (es decir, allí donde se emplean los recursos y conocimientos que están a disposición de los propios usuarios), encontramos siempre edificaciones realizadas en su totalidad con madera y materiales constructivos perecederos. $\mathrm{Su}$ cronología, tal y como hemos visto, se extiende entre el siglo VIII y $\mathrm{X}$.

Desde mediados del siglo $\mathrm{x}$ en adelante, la evolución dentro de este ambiente técnico (la variante técnica) se formaliza con la incorporación de zócalos de piedra que mejoran la durabilidad del material lígneo. Pero, en esencia, la arquitectura doméstica seguirá participando del ambiente 
técnico secular, con los materiales perecederos como elementos constructivos básicos ${ }^{16}$ y ello hasta bien entrado el medievo.

Las construcciones íntegramente en piedra, en cambio, reflejan la presencia de comitentes con importantes recursos, capaces de sufragar los costos derivados de la presencia de grupos de constructores especializados. Esta presencia está constatada, ya para los siglos IX y X, tanto en ciertas iglesias edificadas íntegramente en sillería (Tobillas, Ullíbarri-Arana, Aistra), como en otras de mampostería para el conjunto de su fábrica y sillares para vanos y esquinales (Urbina de Basabe, Samiano, Corro, Astigarribia). En todas ellas es reveladora la utilización del cincel de filo cóncavo para la labra de los materiales.

En otros casos esta influencia está reflejada por la adopción, por parte del ambiente local, de una significativa variante técnica creada a partir de modelos foráneos iniciales: nos referimos a las ventanas monolíticas (escasas en Álava pero numerosas en Vizcaya). Hoy en día están descontextualizadas pero en origen debieron emplazarse en iglesias de pequeñas dimensiones ejecutadas con técnicas de albañil y en las que tampoco sería extraña la utilización profusa de la madera

- Siglo $X 1^{17}$ Esta centuria traerá consigo un importante aumento de la actividad edificatoria. Ello queda bien ejemplificado en las investigaciones llevadas a cabo en el Casco Histórico de Vitoria-Gasteiz, donde para la segunda mitad del siglo se incorporan importantes novedades en las técnicas constructivas con la construcción de la muralla en primer lugar, y de la iglesia inmediatamente después. No desaparecen, sin embargo, las viejas técnicas lígneas, como demuestra la casa tipo Bolckbau que se ha documentado en el subsuelo de la actual catedral y que debe fecharse en un momento avanzado de este siglo.

Como resulta lógico, es en el ámbito de la arquitectura pétrea en el que se aprecian las novedades más interesantes. Nos limitaremos ahora a mencionar únicamente

${ }^{16} \mathrm{El}$ adobe, como material constructivo, y las tejas no están documentadas, de momento, hasta siglos bajomedievales.

${ }_{17}$ Hay una serie de iglesias construidas con materiales procedentes del propio emplazamiento, puestos en obra prácticamente sin tratamiento previo. Un modo de proceder tan empírico resulta difícil de circunscribir en el tiempo y, en cualquier caso, habrá que proceder siempre de manera individual por tratarse de iglesias construidas con técnica de albañil y que no cuentan con variables técnicas o formales que nos permitan una adscripción cronológica general. Aunque algunas pudieran ser anteriores al siglo XI, sus grandes dimensiones y el hecho de que las argamasas sean de una gran calidad nos permiten sospechar que pudiéramos encontrarnos ante ejemplares más bien tardíos y que no fueron construidos por iniciativa campesina. Son los casos de Jugo, Tortura, Hueto Arriba, Ribavellosa, Getaria, Zarautz y Elkano. algunas de las más significativas, remitiéndonos para mayores detalles a la publicación en curso de uno de los autores (SÁNCHEZ ZuFIAURRE, e.p.):

a) Existencia de un taller al norte del territorio alavés, en el entorno del monasterio de San Vicente de Acosta, ámbito geográfico en el que se han documentado templos que, además de mostrar unos rasgos técnicos muy similares, recurren a un mortero producido con arena y cal proveniente del mismo centro extractor. Por primera vez en nuestro ámbito geográfico se ha podido confirmar la presencia de productores de argamasa independientes de los talleres de constructores, dato este de la máxima relevancia. Los edificios resultantes de esta combinación de elementos son las iglesias de Marinda, Gujuli, Olano, Eribe, Gorostiza y Luko.

b) L. Sánchez Zufiaurre defiende, además, la existencia de otro taller muy específico, dedicado a la construcción de un grupo de iglesias ejecutadas prácticamente en serie, caracterizadas por sus saeteras defensivas en el hastial occidental y por su emplazamiento cercano a las principales vías de comunicación. Estas y otras razones llevan a este autor a identificar estas iglesias de su "grupo 6" con la política de control del territorio alavés por parte de la monarquía Navarra que, a mediados del siglo XI (FORTÚN, 1984-1985, 1993: 101-103) aplicaría en Álava la política de obispos-abades que llevaban tiempo implementando en Pamplona. Es así como los abades de Leire se convirtieron en obispos de Álava, sirviendo de agentes del monarca en el territorio

c) Todo ello llevaría a ponderar la importancia de los centros monásticos en la introducción y difusión de las nuevas técnicas edificatorias. El caso de Tobillas (AZKARATE, 2001), tanto en su primera como en su segunda fase, pero sobre todo en la primera ${ }^{18}$, como los casos de San Vicente de Acosta ${ }^{19}$ y

\footnotetext{
18 Para la obra más antigua (ante quem 822) la implicación de los propios monjes se pone de manifiesto en la expresión del abad Avito de que construye la iglesia "con sus propias manos»; frase que, si bien puede ser interpretada como puramente retórica, pone de manifiesto la importancia de la implicación de los monjes en las actividades constructivas.

19 A finales del siglo IX (la primera mención es del año 871) nos consta la aparición del monasterio de San Vicente de Acosta, en las estribaciones meridionales del monte Gorbea. Este centro, a juzgar por las relativamente numerosas menciones documentales, adquiere un dinamismo importante en los años siguientes; esto se constata también a nivel material, ya que probablemente desde el siglo x pero principalmente a lo largo del siglo XI, se va a desarrollar en su entorno una comunidad de constructores y un taller de producción de cal y arena para las argamasas, algo que se refleja en la gran cantidad de iglesias detectadas en la zona de Zigoitia. En este caso, si bien la relación con el monasterio no puede ser establecida de manera directa, la circunstancia de que en su zona de influencia se ponga de manifiesto tal vitalidad en la erección de iglesias de piedra debe ser tenido en cuenta como un aspecto ciertamente significativo.
} 

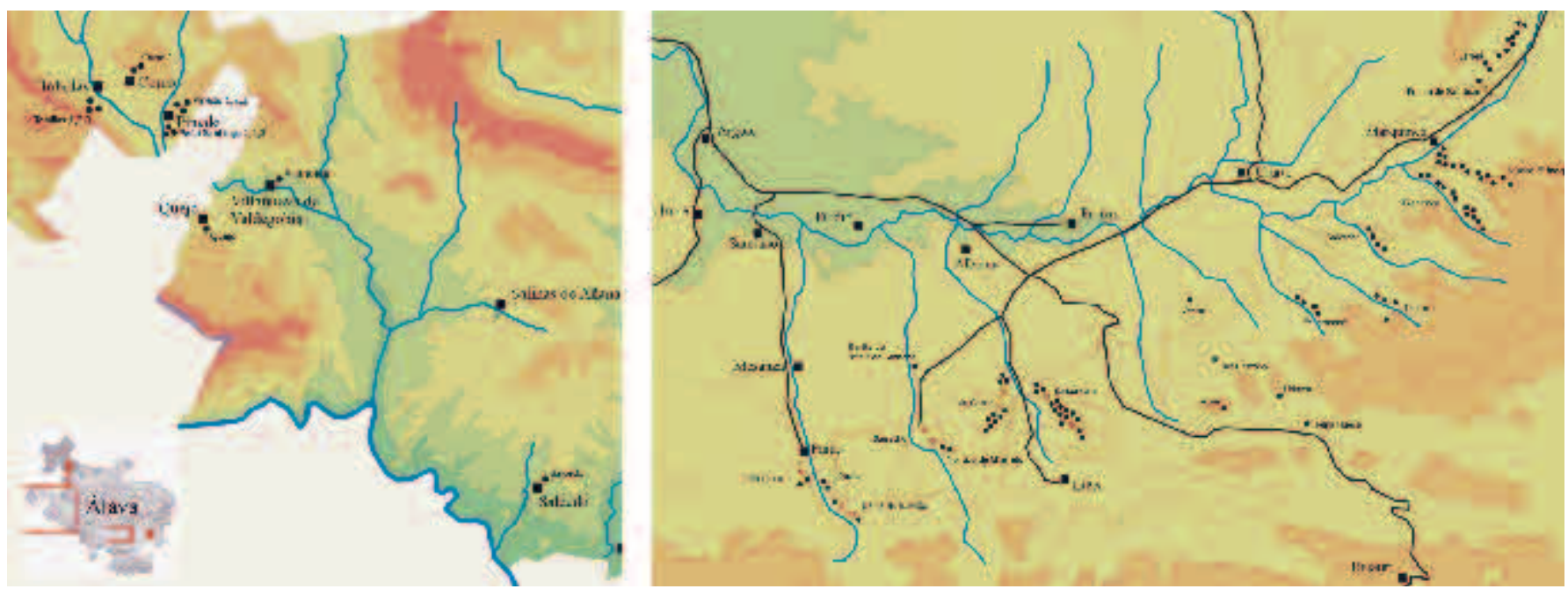

Fig. 10. Distribución de las cuevas artificiales en Alava y Condado de Treviño

de San Andrés de Astigarribia ${ }^{20}$ o lo más evidentes del grupo 6 alavés ${ }^{21}$ constituirían sólidos argumentos para defender esta idea. No se trataría, en definitiva, de una presencia meramente testimonial de los monjes en la edificación de las iglesias en piedra, sino más bien de presencia real y efectiva,

\footnotetext{
20 Para el caso guipuzcoano contamos con San Andrés de Astigarribia, iglesia también perteneciente a un monasterio y que como vimos comparte una serie de características técnicas con numerosas obras alavesas. Dichas similitudes, que se dan también con Tobillas, invitan a pensar en una comunidad de constructores con unos lazos suficientemente estables como para facilitar la transmisión de conocimientos de una manera fluida.

${ }^{21}$ En el tercer cuarto del siglo XI tenemos una de las más importantes evidencias de la actividad constructora de un centro monástico en nuestro territorio; en este caso se trata, además, de la influencia de un cenobio navarro, bastante alejado del espacio alavés, pero que cobra especial relevancia gracias a la influencia de la corona. Como ya hemos dicho antes, se trata del monasterio de San Salvador de Leire. En dicho monasterio, las obras edilicias tienen continuidad desde la década de 1030 en que Sancho el Mayor manda la construcción de la iglesia; ésta es consagrada por Sancho IV el de Peñalén en 1057, y a ella se le adosa el edificio conocido como "monasterio viejo» (LoJENDIO, 1978: 49). En esta obra aparecen saeteras cuya disposición y técnica recuerda en gran medida a las del grupo 6; hemos podido constatar que la obra del «monasterio viejo» de Leire tiene una cronología anterior al siglo XII, gracias a la presencia de una serie de arcos exteriores que formaban una estructura "amatacanada», eliminada a finales del siglo XIX, y cuya datación está bien establecida a lo largo del siglo XII (BONDE, 1994). Esto nos permite considerar como razonable la posibilidad de que el «monasterio viejo» sea la obra que fue consagrada en 1098. Por lo tanto estamos ante la presencia, en la práctica, de un taller de construcción abierto de manera prácticamente continua a lo largo del siglo XI y aún más allá, lo que alimenta la posibilidad de que sean los propios monjes los que se ocupan de dichos trabajos o al menos de su dirección. Y no es nada descabellado contar con que Fortunio, abad de Leire y obispo de Álava a la vez, hubiera contado con los propios monjes de su monasterio para edificar las 6 (cuando menos) iglesias realizadas en serie en territorio alavés (SÁNCHEZ ZuFiaURRE, e.p.).
}

tanto como constructores o como directores de obra. Los monjes, pues, serían los transmisores de los conocimientos que están más allá del ambiente técnico de las comunidades, conocimientos que no sólo se manifiestan en la escritura (el más evidente) sino en otras artes como, en nuestro caso, de carácter constructivo.

\section{ALGUNAS CONSIDERACIONES SOBRE LA ARQUITECTURA RUPESTRE}

Las cuevas artificiales del sur del País Vasco constituyen un fenómeno sorprendente y todavía no valorado suficientemente ni como importante documento histórico de nuestro pasado ni como recurso patrimonial de nuestro presente (Fig. 10).

\subsection{Morfología y funcionalidad}

El centenar largo (118) de cavidades catalogadas en la década de los ochenta (AZKARATE, 1988) se agrupan constituyendo núcleos geográficamente dispersos y conformados internamente por estancias de morfología y funcionalidad distintas. Son cuatro las variables morfológicas que cabe detectar:

a) Cavidades de estancias diversificadas. Constan básicamente de una estancia principal, de planta rectangular, desde la que se accede a otras oquedades a modo de «ábsides», «contraábsides» y «estancias laterales». Cinco de ellas poseen planta basilical de nave única con ábsides contrapuestos en su eje mayor (Montico de Charratu 1, Montico de Charratu 2, Las Gobas 4, Las Gobas 6, y, quizá. Loza 2); cuatro son de planta también basilical aunque con ábside único (Nuestra Señora de la Peña 3 y Santorkaria 5 y, con dudas, Larrea 7) y otras tres - y probablemente también alguna más- son de extraña tipología, como resultado, 
quizá, de las remodelaciones que sufrieron con el tiempo (Nuestra Señora de la Peña 2, San Julián de Faido 2, Santorkaria 12). En todos los casos son estancias de dimensiones reducidas que varían desde los 13,65 metros cuadrados de la más pequeña de ellas (San Miguel de Faido 2) a los 78,90 metros de la más espaciosa de todas (Nuestra Señora de la Peña 2).

Todas ellas fueron utilizadas como espacios de funcionalidad litúrgica. Son 11, al menos, las iglesias que han sido identificadas como tales, aunque es probable que otras cavidades de morfología menos explícita hubieran cumplido también la misma función. Sus ábsides, sus altares de diversa tipología (entalladuras para tenentes cilíndricos o prismáticos, altares adosados), el breve pero rico elenco de inscripciones parietales con advocaciones reivindicando la titularidad del templo, o aclamaciones e invocaciones de profundo carácter cristiano no dejan lugar a dudas en este punto.

Quedan, sin embargo, cuestiones de más difícil resolución, como la presencia repetida de iglesias dúplices ${ }^{22}$ que no cabe despachar con una única explicación tal y como se ha pretendido, recurriendo a argumentos de tipo fructuosiano, por ejemplo. Antes de nada habría que asegurar su coetaneidad en el tiempo, nada clara en algún caso como el de Las Gobas 4 y 6: adscribible la segunda al siglo VII con una razonable seguridad, para la primera en cambio habría que pensar en una cronología bastante posterior.

b) Cavidades de estancia única y fácil acceso desde el exterior. Lo más llamativo de estas estancias es la diversidad de sus principales rasgos. Diversidad en sus dimensiones: la mitad de las cavidades de estancia única que catalogamos en su día (75) tienen unas superficies reducidas de entre 5 y 15 metros cuadrados $(49,39 \%)$ : con una espacio inferior a 5 metros existe una porcentaje del $15,66 \%$; entre 15 y 25 metros un $22,88 \%$ y con más de 25 metros, finalmente, un $12,03 \%$. Diversidad en sus formas: con predominio de las plantas rectangulares y bóvedas rebajadas, aunque en los grupos más orientales es frecuente la planta ultrasemicircular con cubierta de cascarón o cupuliforme. Son muy significativas también las evidencias de cerramientos (unas veces a modo de quicialeras y otras como mechinales ideados para el entrancamiento interior de las puertas) o la presencia de elementos arquitectónicos (repisas, poyos, etc.) que

22 Las Gobas 2 y Las Gobas 4 (Laño), prácticamente contiguas en el farallón rocoso en el que se excavaron; Montico de Charratu 1 y Montico de Charratu 2 (Albaina), hoy desaparecidas pero que fueron también contiguas espacialmente; Nuestra Señora de la Peña 2 y Nuestra Señora de la Peña 3 (Faido), magnífico ejemplo de superposición espacial de dos iglesias rupestres excavadas en un mismo farallón rocoso. hablan bien a las claras sobre su funcionalidad habitacional. Otra cosa distinta, y más compleja, es evaluar la naturaleza de estos alojamientos.

Es probable que ciertas cavidades tuvieran un carácter eremítico y fueran precedentes de centros monacales que nacerían a comienzos del siglo IX en sus inmediaciones. La cercanía de algunas de estas cuevas a reconocidos cenobios altomedievales como Tobillas (Alava) o Valpuesta (Burgos) apuntan en esta dirección. Pero no resulta tan claro en otros casos, aunque nosotros mismos — hace dos décadastratáramos como lauras eremíticas a algunos de los principales complejos rupestres del Condado de Treviño (Burgos). En cambio, cada día estamos más convencidos del tratamiento que deberían recibir muchas de estas cuevas como lugares de habitación de comunidades aldeanas, a las que cabría identificar, quizá, en fechas anteriores a las que tradicionalmente veníamos suponiendo.

c) Cavidades de estancia única y difícil acceso desde el exterior. De planta rectangular unas veces y elíptica y/o circular otras, su rasgo más llamativo es no obstante su espectacular emplazamiento a gran altura, hasta el punto de hacerlas prácticamente inaccesibles. Sus dimensiones varían entre los 10 metros cuadrados de la más pequeña (Peña Hueca (Kruzia) hasta los casi 60 metros de la de San Cristóbal.

Seguimos pensando que estas estancias cumplieron una función relacionada con el almacenamiento, tal y como lo propusimos en su día frente a otras interpretaciones que defendían su condición de lugares de retiro ocasional y/o celdas de castigo en un contexto eremítico generalizado. En realidad no hacíamos sino aceptar la sensata propuesta de los primeros que accedieron a estos difíciles espacios ${ }^{23} \mathrm{y}$ que, tras observar la presencia sistemática de rozas talladas en sus paredes con una separación de un metro aproximadamente, sugirieron que estas acanaladuras pudieran haber servido "para subdividir la habitación en pequeños compartimentos radiales mediante tabiques de madera» transformando, de esta forma, el espacio excavado en un almacén o granero (AZKARATE, 1991: 161-162). Teniendo en cuenta tanto su amplitud como, sobre todo, su emplazamiento en impresionantes peñascos de paredes verticales, sugeríamos también que pudieran haber sido utilizados, ocasionalmente, como lugares de defensa y refugio.

d) Cavidades-nicho. Su rasgo más significativo es su pequeño tamaño, más próximo a una credencia o repisa que a una cavidad en sentido estricto. Llama la atención su presencia en casi todos los grupos, así como el cuidadoso

\footnotetext{
23 Armando Llanos y Nieves Urrutia (miembros fundadores del Instituto Alavés de Arqueología), allá por los años sesenta del siglo XX.
} 
acabado final que ofrecen algunas de ellas, con accesos trabajos en roca en algún caso y pequeños entalles como para acoger algún tenente en algún otro... En definitiva obras intencionadas aunque de función discutible.

\subsection{Génesis y abanico cronológico}

Han transcurrido bastantes años ya desde que propusiéramos algunas ideas básicas tanto sobre los orígenes de estas cavidades como sobre su perduración en el tiempo. Defendíamos entonces tanto la diversidad cronológica del más del centenar de cavidades rupestres catalogadas en Álava y Condado de Treviño (Burgos) advirtiendo que «tan inexacto nos parece el suponer los fenómenos de las cuevas artificiales con vocación exclusivamente eremítica como imaginarlos, en origen, como hábitats de carácter únicamente civil» (AZKARATE, 1988: 477). Concluíamos aquel estudio insistiendo en que debían evitarse «las generalizaciones abusivas referidas a la cronología de las cavidades artificiales alavesas.» (Ibidem: 479-480).

Estas ideas mantienen su actualidad casi dos décadas después, máxime en un contexto historiográfico en el que los distintos modelos interpretativos sobre la evolución del poblamiento desde finales de la Antigüedad hasta bien entrada la Edad Media pugnan entre sí ofreciendo explicaciones totalizadoras y pretendidamente concluyentes.

Frente a estas tentaciones holísticas, hoy tenemos que reivindicar — como entonces - «que los orígenes, cronología y funcionalidad de las cuevas artificiales han de zanjar- se... mediante estudios concretos y puntuales, teniendo en cuenta las distintas ubicaciones, su contexto tanto geográfico como histórico, las diferentes tipologías, las posibles excavaciones arqueológicas... potenciando, en definitiva, los análisis monográficos, previos siempre a cualquier intento de síntesis» (Ibidem: 478).

$\mathrm{El}$ análisis del fenómeno rupestre alavés no hacía sino confirmar este punto de vista, y así lo atestiguaban los datos que fuimos recogiendo en su momento:

1. Existen algunas cavidades, como Montico de Charratu 4, con testimonios epipaleolíticos y neolíticos.

2. Otras como Montico de Charratu 1 y 2 han ofrecido niveles tardorromanos, equivalentes a las ocupaciones troglodíticas del mismo periodo tan extendidas por toda la geografía peninsular y especialmente en la más septentrional.

3. Las Gobas 6 es, quizá, la cavidad más relevante de todas por el potencial interpretativo de sus indicios, especialmente aquellos de carácter epigráfico. Nos encontramos, en general, ante inscripciones escritas en cursiva común romana con mayúsculas intercaladas que reflejan un momento anterior a la formación de la visigótica clásica. Paleográficamente pueden distinguirse hasta cinco manos distintas (AZKARATE, 1991:172-174) que abarcan una horquilla cronológica centrada básicamente en el siglo VII, con alguna prolongación en la centuria siguiente.

4. Junto a esta iglesia de Las Gobas 6, sin embargo, existe otra (Las Gobas 4) con algunos rasgos (fajones, altar en
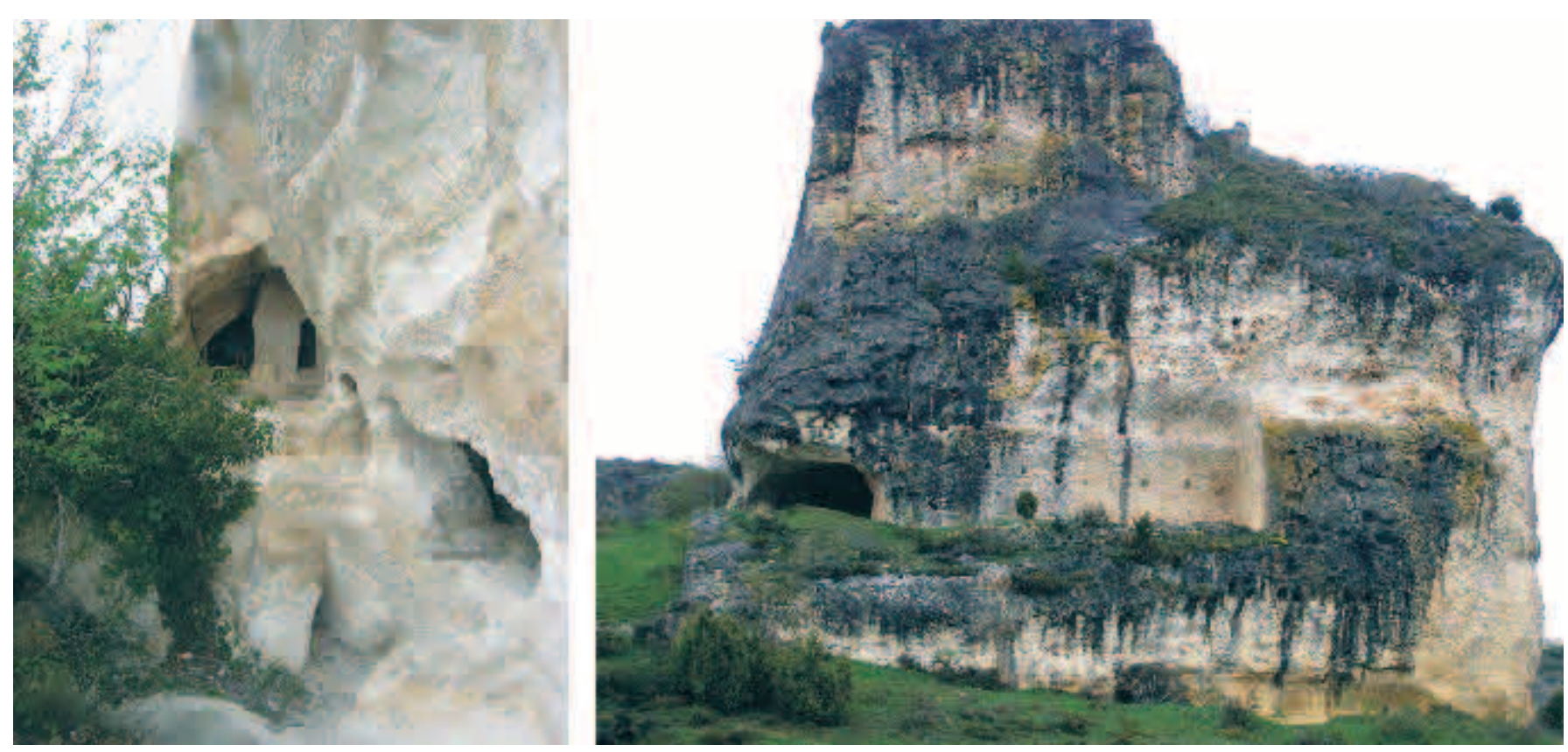

Fig. 11. A la izquierda, imagen parcial del gran complejo rupestre de Santorkaria (Laño). A la derecha, la Peña del Castillo (Larrea), magnífico ejemplo de construcción rupestre complementada con arquitectura lígnea hoy desaparecida 
bloque adosado) que hacen sospechar sobre su cronología algo posterior (ss. IX-X).

5. Los grupos de Marquínez, finalmente (especialmente el de Larrea), parecen incluso más tardíos, tal y como parecen reflejar las antiguas excavaciones de J. M. Barandiarán en la Peña del Castillo.

Es un error, por lo tanto, pretender ofrecer una explicación única para el origen del centenar largo de cuevas artificiales catalogadas hasta el momento. No cabe excluir ninguna propuesta previa para defender otra que, con toda seguridad, será también parcial e insuficiente. Que el arranque de algunas de estas cavidades tenga que ver con la inestabilidad de los siglos bajoimperiales, que otras hayan surgido en el periodo dorado del eremitismo en el que brillaron personajes como San Millán, que sean algo posteriores en el tiempo y deban relacionarse con lugares de habitación y espacios de culto de pequeñas comunidades de inspiración fructuosiana o que no tengan otra explicación sustancial que la ocupación de espacios marginales por poblaciones campesinas de época tardoantigua... es algo que sólo se dilucidará —entre otras cosas y por lo que a nosotros respecta - en la medida en la que seamos capaces de generar registros arqueológicos fiables.

La revisión por parte de uno de los firmantes de este trabajo de este complejo fenómeno tiene como objetivo principal precisamente la consecución de este tipo de registros. Y ello pasa necesariamente por la excavación sistemática de algunos de los lugares más significativos.

\section{Bibliografía}

Ajamil BaÑos J., 2005, Iglesia y necrópolis de San Martín de Rivabellosa (Ribera Baja), Arkeoikuska 2004, pp. 195-201.

Azkarate Garai-Olaun A., 1988, Arqueología Cristiana de la Antigüedad Tardía en Álava, Guipúzcoa y Vizcaya, Vitoria.

Azkarate Garai-Olaun A., 1991, El eremitismo de época visigótica. Testimonios arqueológicos, Codex Aqvilarensis, Cuarto Seminario sobre El Monacato, Aguilar de Campoo, pp. 141-179.

Azkarate Garai-Olaun A., 1995, Aportaciones al debate sobre la arqueología prerrománica peninsular: la iglesia de San Román de Tobillas (Álava), Archivo Español de Arqueología, 68, pp. 188-214.

Azkarate Garai-Olaun A., 2001, Análisis de la evolución históricoconstructiva de la catedral de Santa María de Vitoria-Gasteiz (Aplicación de la "Arqueología de la Arquitectura» a un modelo complejo, Congreso de Arqueología Medieval Española, Valladolid, 1999, Junta de Castilla y León, pp. 177-211.

Azkarate Garai-Olaun A., 2004, Basílica de San Prudencio de Armentia (Vitoria-Gasteiz), Arkeoikuska 2003, pp. 182-187.

Azkarate A., Cámara L., Lasagabaster, J.I., Latorre P., 2001, Plan director para la restauración de la catedral de Santa María de VitoriaGasteiz, Vitoria

Azkarate Garai-Olaun A., Quirós Castillo, J. A., 2001, Arquitectura doméstica altomedieval en la península ibérica. Reflexiones a partir de las excavaciones arqueológicas de la catedral de Santa M. de Vitoria-Gasteiz, País Vasco, Archeologia Medievale XXVIII, pp. 25-60.
Azkarate Garai-Olaun A., SÁnChez Zufiaurre L., 2003, Las iglesias prefeudales en Álava. Cronotipología y articulación espacial, Arqueología de la Arquitectura 2, pp. 25-36.

Azkarate Garai-Olaun A., Solaun Bustinza, J. L., 2003, Después del Imperio Romano y antes del año mil: morfología urbana, técnicas constructivas y producciones cerámicas, Arqueología de la Arquitectura 2, pp. 37-46.

AZKARATE A., LASAGABASTER, J.I., (e. p.), La arqueología y la recuperación de las "arquitecturas olvidadas». La catedral de Santa María y las primitivas murallas de Vitoria-Gasteiz, Congreso Internacional de Restauración. «Restaurar la Memoria. «Arqueología, Arte, Restauración», Valladolid, 2005.

BIANCHI G., 1996, Transmisione dei saperi tecnici e analisi dei procedimenti costruttivi i età medievale, Archeologia dell'architettura I, pp. 53-64.

Bonde S, 1994, Fortress-Churches of Languedoc. Architecture, Religion, and Conflict in the High Middle Ages, Cambridge.

Cepeda Ocampo, J. J., Martínez Salcedo A., 1994a, Buradón. Un conjunto arqueológico singular en la Rioja Alavesa, Revista de Arqueología 156, pp. 38-41.

Cepeda Ocampo, J. J., Martínez Salcedo, A., 1994b, Conjunto arqueológico de Buradón (Salinillas de Buradón, Labastida), Arkeoikuska 93, pp. 257-270.

Cepeda Ocampo, J. J., Martínez Salcedo, A., Unzueta Portilla, M., 1998, Conjunto arqueológico de Buradón (Salinillas de Buradón, Labastida), Arkeoikuska 97, pp. 183-189.

СнареLот O., 1980, Le fond de cabane dans l'habitat rural Ouest-Européen : État des questions, Archéologie Médiévale X, pp. 5-57

CHAPELOt J., Fossier R., 1980, Le village et la maison au Moyen Âge, Paris

Donat P., 1980, Haus, Hof und Dorf in Mitteleuropa vom 7. bis 12. Jahrhundert. Archaeologische Beitraege zur Entwicklung und Struktur der baeuerlichen Siedlung, Berlín

FARNOUX Cl., 1995, Le fond de cabane mérovingienne comme fait culturel, en Lorren C., Périn P., L'habitat rural du Haut. Moyen Age (France, Pays-Bas, Danemark et Grande-Bretagne), Actes des XIVe Journées internationales d'Archéologie mérovingienne, Rouen, pp. 29-44

Fernández Bordegarai J., Apellániz GonzÁlez, J. A., 1996, Necrópolis de la iglesia de San Quirico y Santa Julita, Arkeoikuska 95, pp. 307-312.

Fortún Pérez de CirizA, L. J., 1984-1985, El dominio alavés de San Salvador de Leire, en La formación de Álava: 650 aniversario del Pacto de Arriaga (1332-1982). Tomo I. Comunicaciones I, pp. 339-371.

Fortún PéreZ DE CiriZA, L. J., 1993, Leire, un señorío monástico en Navarra (siglos IX-XIX), Pamplona.

GarCía CAMINo I., 2002, Arqueología y poblamiento en Bizkaia, siglos VI-XII: la configuración de la sociedad feudal, Bilbao.

García Camino I., Neira Zubieta, M., e.p., Ermita de Santa Lucía (Gerrika-Arbatzegi), Arkeoikuska 2006 (e.p.).

GeLICHi S., LibRENTI M., 1997, L'edilizia in legno altomedievale nell'Italia del nord: alcune osservazioni, en I Congresso Nazionale di Archeologia Medievale (Pisa, 29-31 mayo 1997), Florencia, pp. 215-220

GEREÑu URCELAI M., 2001, Intervención arqueológica en la iglesia de San Salvador de Getaria, (memoria).

GianNichedDA E., 2001, Arqueología de la producción, en Francovich, R., Manacorda, D. (eds), Diccionario de Arqueología, Barcelona, pp. 295-301.

GibBOnS M., et alii 1997, La nueva producción del conocimiento, Barcelona. IbáN̄ez EtXeberria A., 2003, Entre Menosca e Ipuscua. Arqueología y territorio en el Yacimiento de Santa María la Real de Zarautz (Gipuzkoa), Zarautz.

IOGNA-Prat D., 2004, Les moines et la «blanche robe d'eglises» à l'âge roman, Ante el Milenario del reinado de Sancho el Mayor. Un rey navarro para España y Europa. (Actas de la XXX Semana de Estudios Medievales de Estella. 14 al 18 de julio de 2003), pp. 319-347.

LATORRE P., 1996, La arqueología de la arquitectura. Consecuencias metodológicas de su aplicación al proyecto de restauración, en Actas Arqueología de la Arquitectura. El método arqueológico aplicado al proceso de estudio y de intervención en edificios históricos. 
Leroi-Gourhan A., 1989, El medio y la técnica, Madrid.

Lojendio, L. M., 1978, Navarra. (La España Románica, Volumen 7), Madrid.

LOPEZ QUiroga J., 2004, El final de la antigüedad en la Gallaecia: la transformación de las estructuras de doblamiento entre Miño y Duero (siglos $V$ al X), Santiago de Compostela.

MANNONI T., 1997, Il problema complexo delle murature storiche in pietra. 1. Cultura materiale e cronotipologia, Archeologia dell'Architettura, II, pp. 15-24.

Mannoni, T., Giannichedda E., 2004, Arqueología de la producción, Barcelona.

Pérez Centeno J., Piá Aranguren A., 2001, San Andrés de Astigarribia (Mutriku), Arkeoikuska 00, pp. 94-98.

Pérez Centeno J., Piá Aranguren A., 2002, San Andrés de Astigarribia (Mutriku), Arkeoikuska 01, pp. 132-134.

Pérez Centeno J., Piá Aranguren A., 2003, San Andrés de Astigarribia (Mutriku), Arkeoikuska 02, pp. 120-121.

PESEZ J. M., 1985, Le renaissance de la construction en pierre après l'an Mil, en Pierre et métal dans le bâtiment au Moyen Âge. Études réunies par O. Chapelot et P. Benoît, Paris, pp. 197-217

SÁENZ De URTURi F., 1984-86, Los Castros de Lastra, Arkeoikuska 83, 84, 86, Vitoria.

SÁENZ DE URTURI F., Memoria de los sondeos estratigráficos realizados en las inmediaciones de las "Cuevas de los Moros» (Corro, Alava), Estudios de Arqueología Alavesa, 17, pp. 179-219.
SÁnCheZ Zufiaurre L., 2003, Iglesia de San Andrés de Astigarribia (Mutriku), Arkeoikuska 2002, pp. 178-187

SÁnChEZ ZufiaurRe L., 2005, Iglesia de San Quirico y Santa Julita de Uribarri-Kuartango (Kuartango), Arkeoikuska 2004, pp. 301-306.

SÁnCheZ Zufiaurre L., (e.p.), Técnicas constructivas medievales. Nuevos documentos arqueológicos para el estudio de la Alta Edad Media en Álava, Vitoria-Gasteiz.

SANTANA EZKERRA A., (coord.), 2003, Igartubeiti, un caserío guipuzcoano: investigación, restauración, difusión, Donostia-San Sebastián.

Solaun Bustinza, J. L., 2005, La cerámica medieval en el País Vasco (siglos VIII-XII). Sistematización, evolución y distribución de la producción, Vitoria-Gasteiz.

TORRECILLA, M. J., 2003, Igartubeiti, investigación arqueológica de un caserío, en SANTANa EzKERRA A., (coord.), Igartubeiti, un caserío guipuzcoano: investigación, restauración, difusión, Donostia-San Sebastián, pp. 151-169.

Urteaga Artigas, M. M., 2004, Cripta arqueológica de San Salvador de Getaria. Proyecto de rehabilitación, Boletín Arkeolan 12, pp. 11-17.

VALENTi M., 1996, Poggio Imperiale a Poggibonsi: dal villaggio di capanne al castello di pietra. I. Diagnostica archeologica e campagne di scavo 1991-1994, en Biblioteca del Dipartimento di Archeologia e Storia delle Arti, 1, Florencia.

Zaldua Goena, M. J., 1989, Ermita de S. Pedro de Elcano (Aia, Guipúzcoa): I campaña de excavaciones, Arkeoikuska 88, pp. 42-45. 